\title{
Article \\ Numerical Modelling on the Local Design of a Marine Bonded Composite Hose (MBCH) and Its Helix Reinforcement
}

\author{
Chiemela Victor Amaechi ${ }^{1,2, *(D)}$, Cole Chesterton ${ }^{3}$, Harrison Obed Butler ${ }^{4}$, Zewen Gu ${ }^{1}$ \\ and Agbomerie Charles Odijie 5
}

1 Department of Engineering, Lancaster University, Lancaster LA1 4YR, UK; z.gu4@lancaster.ac.uk

2 Standardisation Directorate, Standards Organisation of Nigeria (SON), 52 Lome Crescent, Wuse Zone 7, Abuja 900287, Nigeria

3 Power Plant Development Department, EDF Energy, Bridgewater House, Counterslip, Bristol BS1 6BX, UK; cole.chesterton@sky.com

4 DTU Energy, Danmarks Tekniske Universitet (DTU), 2800 KGS Lyngby, Denmark; s192084@student.dtu.dk

5 Engineering Department, MSCM Ltd., Coronation Rd., High Wycombe HP12 3TA, UK; charlesodijie@hotmail.com

* Correspondence: c.amaechi@lancaster.ac.uk

Citation: Amaechi, C.V.; Chesterton, C.; Butler, H.O.; Gu, Z.; Odijie, A.C. Numerical Modelling on the Local Design of a Marine Bonded Composite Hose $(\mathrm{MBCH})$ and Its Helix Reinforcement. J. Compos. Sci. 2022, 6, 79. https://doi.org/ $10.3390 /$ jcs 6030079

Academic Editor: Jiadeng Zhu

Received: 14 January 2022

Accepted: 21 February 2022

Published: 3 March 2022

Publisher's Note: MDPI stays neutral with regard to jurisdictional claims in published maps and institutional affiliations.

Copyright: (C) 2022 by the authors. Licensee MDPI, Basel, Switzerland. This article is an open access article distributed under the terms and conditions of the Creative Commons Attribution (CC BY) license (https:// creativecommons.org/licenses/by/ $4.0 /)$.

\begin{abstract}
With the exploration of oil trending deeper, from shallow waters to deep waters, there is a corresponding increase in the need for more sustainable conduit materials for production purposes. Secondly, there is an increasing demand for more energy from fossil fuels that are excavated with less expensive technologies. As such, short-service hoses are applied in the offshore industry. The industry has utilised composites to improve the material and solve different offshore issues. This study analyses a current problem facing the oil and gas industry at present regarding hose usage. This paper presents results from the local design and analyses of a marine bonded composite hose (MBCH), to present its result visualisations and nephographs. In this paper, the local design of a $1 \mathrm{~m}$ section of an $\mathrm{MBCH}$ was carried out in ANSYS under different loading conditions. Some design criteria were set, and other load conditions were used to simulate the model using the finite element model (FEM) approach. From this study, composites could be considered to improve conventional marine hoses. The findings of the study include the identification of linear wrinkling and damage sites on the helix reinforcement. An experimental investigation and proper content test are recommended for the bonded hose. Additionally, highly reinforced hose ends are recommended in the ends of the $\mathrm{MBCH}$, as they had maximum stress and strain values. It is recommended that hose operations like reeling must be conducted under operational pressure and not design pressure, as the study shows that the design pressure could be high on the hose model.
\end{abstract}

Keywords: numerical model; finite element model (FEM); marine bonded composite hose; composite riser; layered marine structures; liner wrinkling; helix spring; stress analysis; bonded model

\section{Introduction}

Floating structures need to be stable, float, withstand adverse weather conditions and also carry the load from their attachments [1,2]. These structural attachments include marine risers, mooring lines, umbilicals, subsea cables and marine hoses [2,3]. Considering the increasing demand for the utilisation of more marine composites in the oil and gas industry, more investigations have been conducted on the subject area [4,5]. Ochoa and Salama [6] presented transition barriers that can be considered to be an enabling technology for offshore composites, such as composite risers. Rubino et al. [7] presented a review of marine composites in ships, submarines, remotely operated vehicles (ROVs) and water airplanes. These reviews showed recent developments, challenges and an overview on the behaviour of marine composites under different conditions. This includes the use of marine composites as composite marine risers [2-7]. Thus, with the exploration of oil trending 
deeper from shallow waters to deep waters, there is a corresponding increase in the need for more sustainable conduit materials for production purposes [8-13] as well as novel floating structures to support these hose-risers [14-19]. Thirdly, there is an increasing demand for more energy from fossil fuels excavated with less expensive technologies. As such, shortservice marine hoses are applied in the offshore industry [20-25]. The industry has utilised composites to improve the material and solve different offshore issues. However, buckling, liner failure, delamination and matrix cracking in the layers of marine tubular structures are common failure problems, especially when the structures are multi-layered [26-30]. Composite tubes and hoses have shown similar mechanical behaviour [31-36]. Thus, the marine bonded composite hose $(\mathrm{MBCH})$ is a solution presented in this study to alleviate a current problem in the oil and gas industry regarding reeling hoses. The dynamic reaction of the marine hoses when coupled to the CALM buoy has been studied in various ways [3743]. In recent years, the oil and gas industry has used a diverse range of materials to manufacture marine hoses, such as elastomers. These can be found in a variety of hose materials from hose manufacturing companies such as Dunlop Continental Oil and Gas, Yokohama and Trelleborg, among others [44-48]. One challenge with using marine hoses is the assessment of fatigue load due to their behaviour relative to the utilisation in sea conditions [49]. Figure 1 shows a field deployment of Trelleborg's Sealine floating hose.

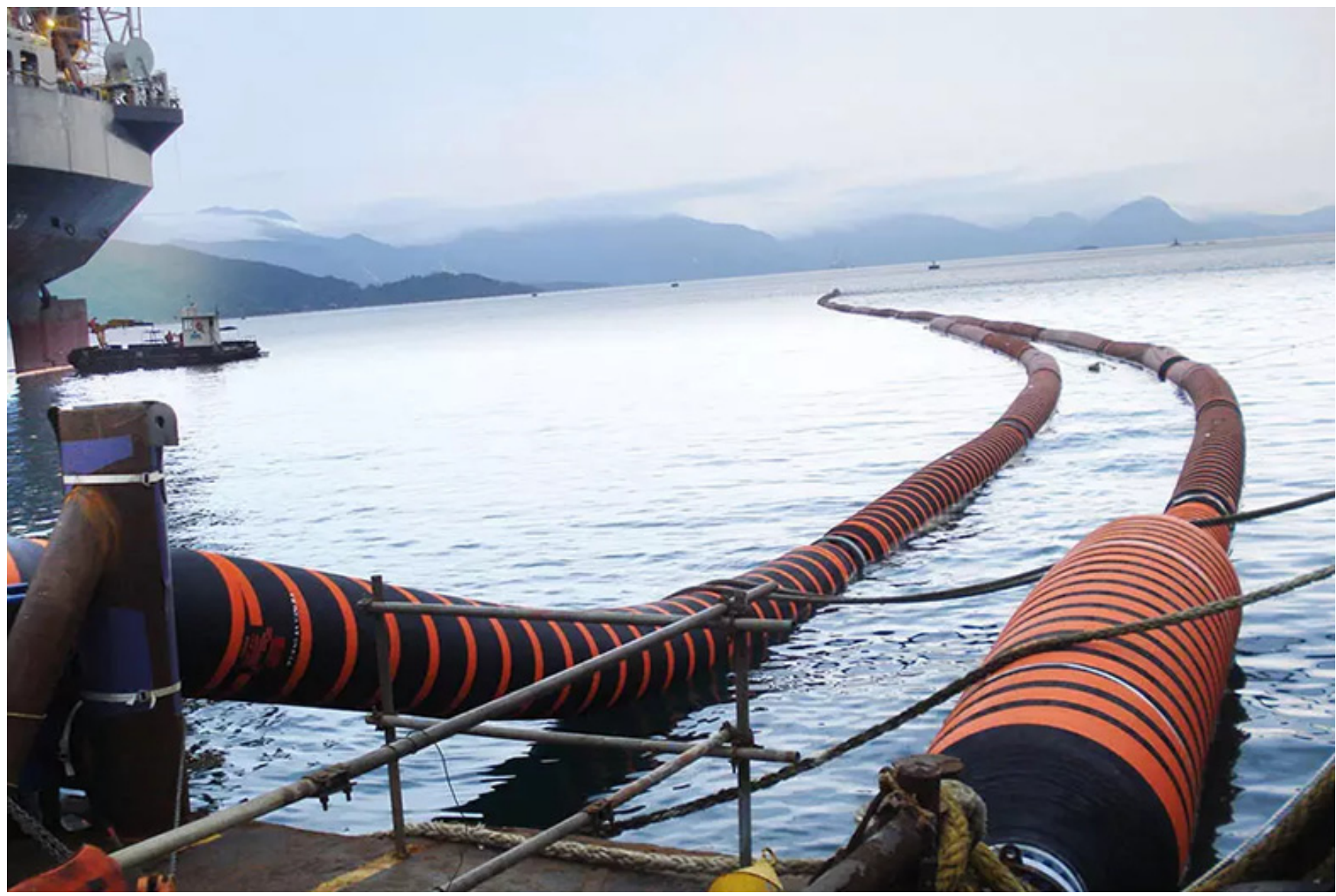

Figure 1. Trelleborg's Sealine floating hose during installation to a supply vessel. (Sealine is a product type that is specifically designed for floating hose configurations, while Reeline is a product type that is specifically designed for reeling hose configurations. Both Sealine and Reeline are hose products made by Trelleborg, a hose manufacturer. Courtesy: Trelleborg; adapted with permission.).

The industry has advanced with the unique application of composites over the past two decades. Generally, composites have high applicability in marine environments, such as in thermoplastic composite tubes (TCP) and composite production risers (CPR) [50-53]. 
This is due to their inherent properties, such as their high strength, light weight, high resistance to corrosion, high flexibility and some anisotropic characteristics. This anisotropy implies that the material has properties that allow it to change or adapt into different properties in different directions, instead of isotropy. It should be noted that anisotropy can be predicted and evaluated; hence, there are no assumptions. However, some analytical models consider some assumptions in the formulation of the composite theory. Xia et al. [54] investigated the internal pressure of multi-layered filament-wound composite pipes. They used a cylindrical pipe section to offer analytical formulations for the composite elastic theory, which took into account three-dimensional (3D) elastic constants with effective properties for the thick laminates discovered in an earlier study by Sun and Li [55]. Ye and Soldatos [56] looked into 3D buckling analysis of laminated composite hollow cylinders and cylindrical panels and gave buckling mode profiles. Bakaiyan et al. [57] investigated multi-layered filament-wound composite pipes with thermal fluctuations under combined internal pressures and thermomechanical loads. Gao et al. [58] evaluated the structural behaviour of a ring-stiffened rubberised composite hose specialised for use as a dredging hose under internal pressure. Lassen et al. [59] experimentally validated the marine hose to investigate the ultimate strength of the hose model. Some other similar models based on the mechanical behaviour of marine hoses were also devised by other researchers. Tonatto et al. [60] presented a comparison between the results of computational analysis and experimental analysis. Tonatto et al. [61] numerically investigated the mechanical behaviour of the marine hose model under burst load. These studies also showed that composites can be used in marine structures. Amaechi et al. [62] presented an experimental investigation on the CALM buoy hose system to assess the influence of waves under moored and free-floating conditions. Other investigations were conducted by considering the use of composites in marine hoses. Different studies have shown that composite materials can survive seawater ingress at different levels based on individual material properties. Hassan et al. [63] studied the effect of seawater on marine composites by using glass fibre/epoxy laminates to investigate fracture toughness. Bearing this information in mind, the application of composites can be deployed to improve the material strength, flexibility, stiffness ratio and other mechanical behaviours of the marine bonded hoses. Currently, marine bonded hoses have a short service life and may fail prematurely under adverse conditions and different failure modes [64]. There has been widespread awareness of both layer delamination and reinforcing helix ruptures in the helix. The reinforcement helix made of bonded flexible hose lines is a special area for hose observation and interest in the offshore oil and gas sector. These hose lines have been reported to collapse long before their predicted lifetime of roughly 25 years due to structural issues pertaining to the bonded helix in several cases. This occurs due to layer delamination between the helix and the surrounding filler, or the full failure of the helix itself, according to common observations. If one of these events occurs, the entire pipeline segment will need to be replaced. To push this hose line technology further, extensive simulation and study of the helix design is required. Several ideas exist to explain the reason for the occurrence of marine hose failure or the malfunction of its valve or end-fitting connection. One reason is fatigue, which leads to eventual rupture owing to the ovalisation of the helical structure under compressive force. The marine hose structure is usually subjected to compressive loading from other spooled sections, the reel drum itself (for reeling hoses) or a combination of both during operation. Throughout the service life of the hose, these crush loads will be applied continuously with repetitive moments and tension loads. The helical structure may also be subjected to fatigue cracking as a result of this type of repetitive loading. The shape of the helix will begin to ovalise as it is compressed, posing a high risk of cracking. As a result, some researchers have confirmed that helix reinforcement is very vital in the marine hose structure $[65,66]$. Gao et al. [65] analytically investigated the spiral stiffeners for offshore composite rubberised hoses under burst load, while Lassen et al. [66] investigated helix reinforcement and the load response of a marine bonded hose. The latter found that found the cradle's angle in the helix contributed to its strength. Tonatto et al. [67-69] investigated 
the crush load and mechanical behaviour of a marine hose, but did not conduct crush load testing on the reinforcement. The crush load for helical spring specification is not specified in the Oil Companies International Marine Forum (OCIMF)'s industry guidelines [70-72]. The GMPHOM OCIMF 2009 guidance [72], on the other hand, establishes guidelines for a marine hose segment, but not for the helix reinforcement. It specifies conducting a shorter test with a profiled hose section with a nominal length of $500 \mathrm{~mm}$, which is supported on a flat surface. For instance, it also specifies that a crushing load be applied to the hose using a flat beam with a profile of $500 \mathrm{~mm}$ length-wise and $400 \mathrm{~mm}$ width-wise, according to the test conditions. Gonzalez et al. [73] looked at the axial characteristics of flexible bonded marine hoses and showed interesting bending profiles, but he did not provide detail on the reinforcement. An earlier study by Chesterton [74] was conducted on the reeling hose model with the spring's crush load against the reeling drum, and he found that the helix deforms as well. Zhou et al. [75] presented a theoretical model on marine hose reinforcement, while Tonatto et al. [76] experimented with helix reinforcement materials for marine hoses using composite materials and conducted some crush load tests on the hose. Hence, it is critical to investigate the helix by simulating this loading condition in order to better understand the helix's mechanical behaviour as a result of crush loads. Internal pressure loads were identified as the most essential load based on the highest stresses on the layers of the hoses tested during the investigations. The material modelling of the composite tubular structure or its helical spring reinforcement are also difficult. As a result, there is a pressing need for a deeper grasp of the industry's current problems, both locally and globally. This will progress the usage of composites in hose-riser applications even further.

Using numerical modelling, this study contains investigations into the local design of marine bonded hoses and their helix reinforcement behaviour. The goal was to model a straight portion of the tubular marine riser construction based on the local design, then present its result visualisations and nephographs. For the multi-layers, bonded connections were used. It was feasible to simulate the stresses exerted on this segment of the hose-riser using the modelling in Sections 2 and 3. Section 2 present the material properties while Section 3 deals with the details for the numerical modelling using a finite element model (FEM). Section 4 provides the findings of the numerical modelling for the unique $\mathrm{MBCH}$ structure, and some result discussions. The concluding observations and recommendations drawn are delivered in Section 5.

\section{Materials and Methods}

\subsection{Model Description}

ANSYS Structural version R2 2020 [77-79] was used for the local design of the marine hose. Sections 2.3 and 2.4 detail the hose's geometric specifications as well as its material qualities. The ANSYS Workbench's Engineering Data were used to determine the material properties loaded into the platform. Then, the various physics explored on the loading requirements of the marine reeling hose were imputed in ANSYS Mechanical. This was then meshed, and convergence was checked in order to present accurate data for both static and dynamic behaviours. Due of the need to predict demand for a different package in modelling this marine hose, ANSYS Structural's benchmark was utilised rather than ANSYS APDL in this investigation. It is worth noting that this is a multi-layered marine structure with numerous layers and contacts. As a result, under higher licences, the ANSYS platform's performance was limited to running the ANSYS model with higher element numbers while generating faster results. Furthermore, there was a restriction on using HPC (high-performance computers) to execute the FEA for this model. Ultimately, symmetry was addressed in this model, but not implemented in the current investigation, though it was in another study that is not included in this paper. Due to the sheer spiral structure of the spring in this investigation, symmetry was not very representative. However, as was discovered in the second model employed in a subsequent investigation, it might 
have decreased the computing cost, but not in this case. Figure 2 depicts two hose sections showing the reeled and unreeled hose sections.

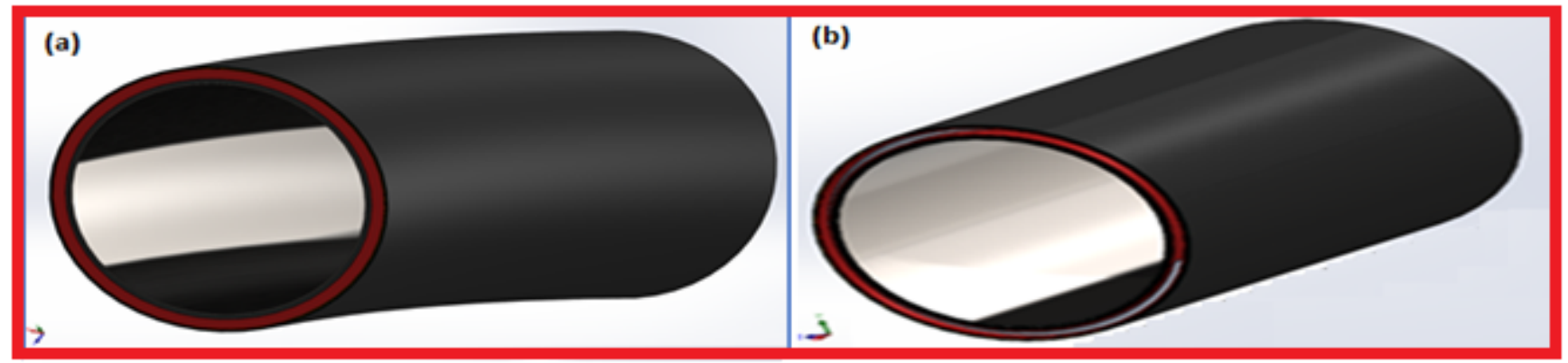

Figure 2. Marine hose model showing (a) reeled section representing a bending curvature section, and (b) unreeled section representing a straight section in Solidworks version 2020.

\subsection{Methodology}

The hose geometry was developed in a CAD using Solidworks version 2020 for the local design. Since it featured composite layers, it was then modelled in ANSYS Structural version R2 2020 and ANSYS Mechanical modules. The composite layers were used as homogenised layers incorporated from the ANSYS Engineering Data module. The hose's FEM data from the local design were analysed in order to anticipate its mechanical behaviour. These assessments were carried out by considering some factors for obtaining the best results from the model. The first priority was to make the model simpler, and the second was to make the model homogeneous. Figure 2 depicts the first simple model as well as the separate helix spring. The development of the marine hose model, material properties, the behaviour of physical hose models, boundary conditions and the analysis and evaluation of results were all part of the approach for the FEM of the marine bonded hose. Internal pressure, external pressure and the load case were all included in the finite element analysis (FEA). Figure 3 shows a schematic representation of the FEM applied methodology.

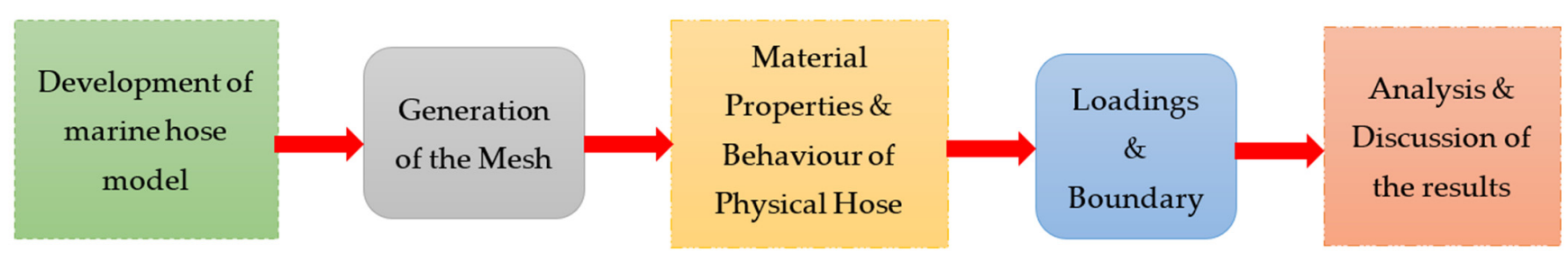

Figure 3. Methodology for the numerical model of the marine bonded composite hose model.

\subsection{Material Properties}

Table 1 lists the material parameters taken into account in this model for steel and the composites. These material qualities were chosen because they have a lot of potential for use in flexible bonded hose lines and other modern industrial applications. As a result, they were deemed suitable for use in the design of this model in order to achieve accurate simulation results. They have a lot of upsides because of their unique characteristics, including their high strength, natural corrosion resistance, light weight and flexibility. The connection details under consideration were bonded contacts that were properly retained, with no slippage or separation. Table 1 lists the material attributes used in the computational model. For the composites, this model used the same hoop layers with a $0^{\circ}$ orientation angle. The layers and material choices examined in this model are listed in Table 2. 
Table 1. Material properties for composites and steel.

\begin{tabular}{|c|c|c|c|c|c|c|c|c|}
\hline Material ** & $\begin{array}{l}\text { Density } \\
\left(\mathrm{kg} / \mathrm{m}^{3}\right)\end{array}$ & $\begin{array}{c}\text { Youngs } \\
\text { Modulus (Pa) }\end{array}$ & $\begin{array}{c}\text { Bulk } \\
\text { Modulus (Pa) }\end{array}$ & $\underset{(\mathrm{Pa})}{\text { Shear Modulus }}$ & $\begin{array}{l}\text { Compressive Yield } \\
\text { Strength (Pa) }\end{array}$ & $\begin{array}{l}\text { Tensile Yield } \\
\text { Strength (Pa) }\end{array}$ & $\begin{array}{l}\text { Tensile Ultimate } \\
\text { Strength (Pa) }\end{array}$ & $\begin{array}{l}\text { Poisons } \\
\text { Ratio, } v\end{array}$ \\
\hline Structural Steel & $7.85 \times 10^{3}$ & $2.00 \times 10^{11}$ & $1.67 \times 10^{11}$ & $7.69 \times 10^{10}$ & $2.50 \times 10^{8}$ & $2.50 \times 10^{8}$ & $4.60 \times 10^{8}$ & 0.30 \\
\hline Nylon PA6/6 & $1.14 \times 10^{3}$ & $1.06 \times 10^{9}$ & $1.18 \times 10^{9}$ & $3.93 \times 10^{8}$ & $2.32 \times 10^{9}$ & $4.31 \times 10^{7}$ & $4.97 \times 10^{7}$ & 0.35 \\
\hline Nylon PA66-GF * & $1.36 \times 10^{3}$ & $6.82 \times 10^{9}$ & $7.58 \times 10^{9}$ & $2.53 \times 10^{9}$ & $3.45 \times 10^{7}$ & $1.39 \times 10^{8}$ & $1.49 \times 10^{8}$ & 0.35 \\
\hline $\mathrm{CF}(290 \mathrm{GPa})^{+*}$ & $1.81 \times 10^{3}$ & $2.9 \times 10^{11}$ & $2.45 \times 10^{11}$ & $9.00 \times 10^{9}$ & $5.70 \times 10^{8}$ & $4.20 \times 10^{9}$ & $6.00 \times 10^{8}$ & 0.30 \\
\hline Resin Polyester & $1.20 \times 10^{3}$ & $3.0 \times 10^{9}$ & $2.72 \times 10^{9}$ & $1.14 \times 10^{9}$ & $1.41 \times 10^{8}$ & $1.28 \times 10^{8}$ & $5.18 \times 10^{7}$ & 0.32 \\
\hline
\end{tabular}

** Material properties in MatWeb, Granta and [9]. ${ }^{+*} \mathrm{CF}$ is carbon fibre. ${ }^{*} \mathrm{GF}$ is glass fibre-reinforced.

Table 2. Material consideration for reeled hose layers.

\begin{tabular}{|c|c|c|c|c|c|c|c|c|}
\hline Layer & Liner & Main Plies & Filler & Helix & Holding Plies & Subcover & Breakers & Cover \\
\hline Material & Structural Steel & $\begin{array}{l}\text { Glass fibre-reinforced } \\
\text { nylon } 6 / 6 \text { (PA66-GF) }\end{array}$ & Nylon 6 (PA6) & Structural Steel & Resin polyester & $\begin{array}{c}\text { Carbon fibre } \\
(290 \mathrm{GPa})\end{array}$ & $\begin{array}{c}\text { Resin } \\
\text { polyester }\end{array}$ & $\begin{array}{c}\text { Carbon fibre } \\
\text { (290 GPa) }\end{array}$ \\
\hline
\end{tabular}

\subsection{Marine Hose Layers}

In order to achieve the best simulations, the details of the marine hose design are taken into consideration as described in this section. It is indeed worth noting that the simulation layers in marine hose designs are based on typical realistic hoses. However, to correctly replicate the hoses without sacrificing generality, simplification was required. The usage of innovative composite materials employed in these designs is a top priority in this research. As a result, distinct composite plies were used in the model for the main and holding plies. To give structural strength to the construction, the subcover and cover were composed of structurally robust composites. On the other hand, the steel structural helix buried within the filler layers is an important part of the hose's tubular design. It differs from standard marine risers, pipe-in-pipe tubes and looped steel pipes in this way. Since helix rupture or delamination from its filling layer is a common fault in these hose-riser structures $[26-30,64]$, the helix reinforcement is given particular attention. The function of the steel helix is to give strength by acting as an important longitudinal reinforcement to the pipeline. Figure $4 \mathrm{a}$ shows the model for the steel reinforcement, while Figure $4 \mathrm{~b}$ shows a mesh model of the simplified hose model. Thus, this layer is very crucial for investigating the structural behaviours of the hose, such as deformation performance. As a result, a thorough examination of this layer for the helix is required. Table 3 provide the layer's geometrical data for the marine hose models. The dimension for each layer was determined, and is as represented in Figure 5. Details of the dimensions are given in an earlier study [21].
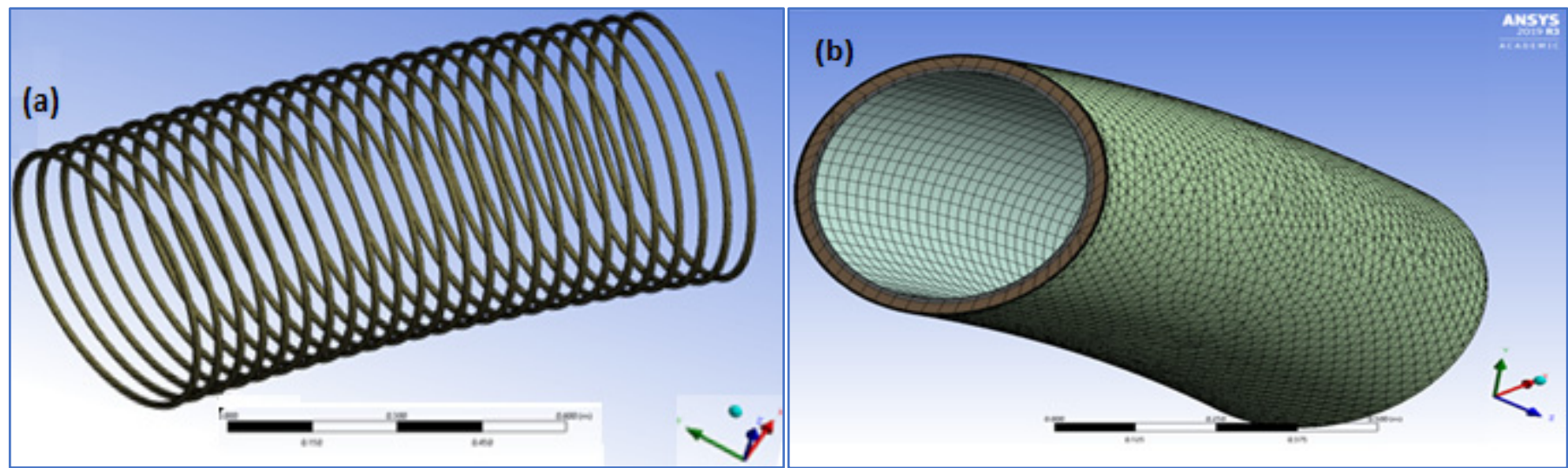

Figure 4. Mesh model of the (a) helix reinforcement and (b) simplified marine hose model. 
Table 3. Marine hose model dimensions.

\begin{tabular}{|c|c|c|c|}
\hline Layer & Outer Diameter (mm) & Inner Diameter (mm) & Thickness (mm) \\
\hline Liner & 493.95 & 488.95 & 5 \\
\hline Main ply 1 & 496 & 493.95 & 2.05 \\
\hline Main ply 2 & 498.05 & 496 & 2.05 \\
\hline Main ply 3 & 500.1 & 498.05 & 2.05 \\
\hline Main ply 4 & 502.15 & 500.1 & 2.05 \\
\hline Main ply 5 & 504.4 & 502.15 & 2.25 \\
\hline Main ply 6 & 506.25 & 504.4 & 1.85 \\
\hline Main ply 7 & 508.3 & 506.25 & 2.05 \\
\hline Main ply 8 & 510.35 & 508.3 & 2.05 \\
\hline Filler 1 & 517.35 & 510.35 & 7 \\
\hline Steel helix & 545.79 & 517.35 & $14.22 *$ \\
\hline Filler 2 & 552.79 & 545.79 & 7 \\
\hline Holding ply 1 & 554.84 & 552.79 & 2.05 \\
\hline Holding ply 2 & 556.89 & 554.84 & 2.05 \\
\hline Subcover & 559.39 & 556.89 & 2.5 \\
\hline Breaker 1 & 560.59 & 559.39 & 1.2 \\
\hline Breaker 2 & 561.79 & 560.59 & 1.2 \\
\hline Cover & 564.29 & 561.79 & 2.5 \\
\hline
\end{tabular}

Note: Radius of curvature of marine hose layer $=6.25 \mathrm{~m} ;{ }^{*}$ coil diameter is not the overall diameter.

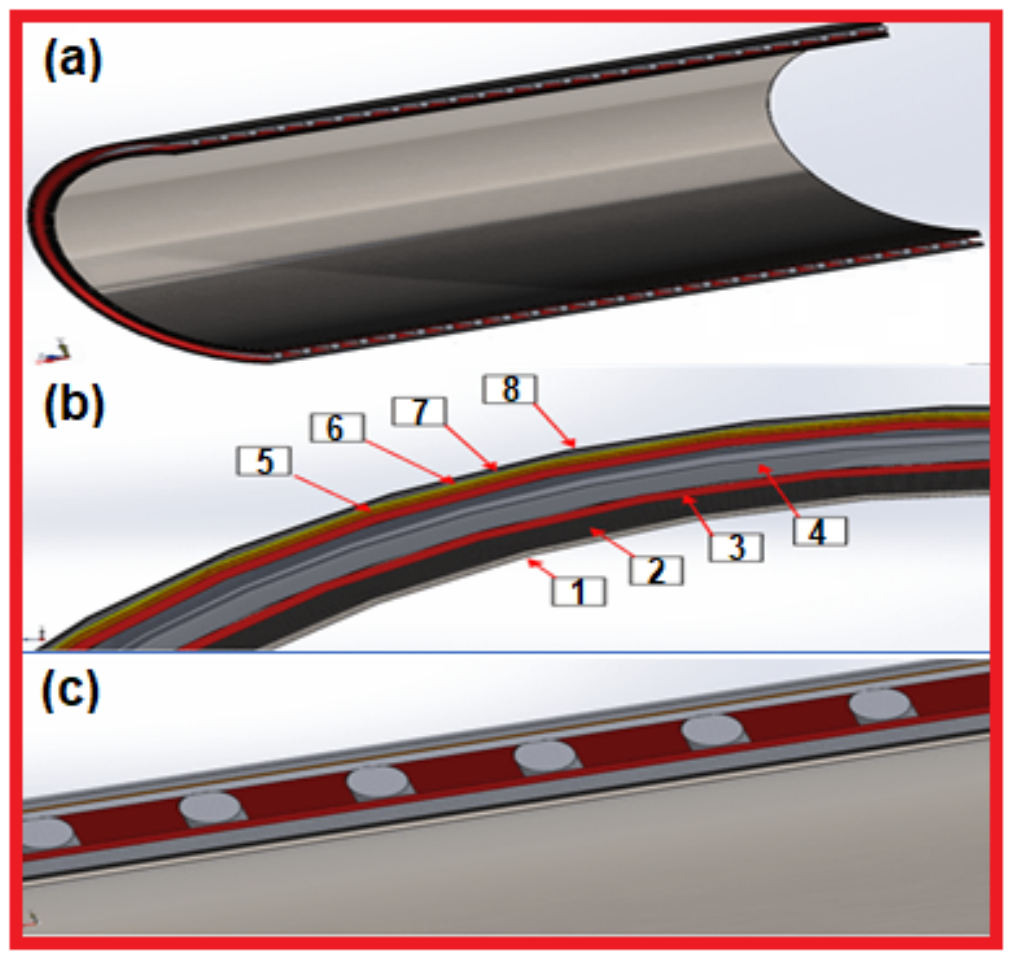

Figure 5. Cross-section through hose showing layers with the helix reinforcement in (a) open view, (b) closed view and (c) labelled section of layers for the liner (1), main plies (2), filler (3), steel helix (4), holding plies (5), subcover (6), filler (7) and main plies (8). 
This model set-up is based on industry standard practices to appropriately portray the hose. The 'main plies' of the composite are of varied angles in practice, while the helical reinforcing layer is completely encased in a single filler layer. The scope of the current investigation, however, did not include research on the reinforcement angles. In terms of composite material choices, different materials have been chosen for different layers of the model. For the inner liner and reinforcing helix, steel was used as the metallic component of the model. Resin polyester, carbon fibre (290 GPa), nylon 6 (PA6) and glass fibre-reinforced nylon 6/6 (PA66-GF) were also the choices of composite materials applied. The material properties were obtained from validated studies, published journal papers, company reports, material databases and previous investigations [53-55]. The hose in this present model measures 1 metre lengthwise.

Rather than being modelled within one filler layer, it was modelled with filler layers sandwiching the helix between them. This was implemented to keep the model design simple during the CAD stage, making the hose assembly easier while yet providing adequate simulation results. This method has been applied in modelling composite tubular pipes, ranging from CPR [31-36], to TCP/FRP composite riser tubes [51-53], composite pipes [54-57] and $\mathrm{MBCH}$ [58-61]. To replicate a localised part of the hose line receiving crush load from the reel drum, the same layering method was used to construct both a reeled and unreeled model using the same layering technique. To accurately imitate the pipe being put over the reel drum of diameter $12 \mathrm{~m}$, the reeled riser model was created with a radius of curvature of $6.25 \mathrm{~m}$. The first simulation material selection for the various layers is detailed herein. It is worth noting that at this point, different ply angles have not been used because the major goal was to obtain a workable case from the simulation to begin with. As a result, the ply angles in the hoop direction were all assumed to be unidirectional. Lastly, for this model, the helix was not modelled in a reeled state, as was earlier conducted, but in a straight and unreeled format.

\section{Numerical Model}

The details on the numerical model for the $\mathrm{MBCH}$ is carried out in this section.

\subsection{Local Design}

The local design aspect of the numerical model was conducted using FEM. The FEM model was developed using ANSYS Workbench R2 2020. The local design details are described in Section 2, whereas the mesh details, boundary conditions and design loads are all presented in Sections 3.2-3.5. The maximum stress criterion is used as the failure criteria in this model. The beam theory is used in the local design of the marine hose.

\subsection{Mesh Details}

The meshing details for the initial reeled model include a total of 857,215 elements and $5,395,485$ nodes. This gave good convergence results in this FEA. To achieve this, the mesh was simplified and compared using a hose model without the spring. This model was also further simplified by collectively grouping the similar layers into one layer, i.e., main plies 1-8. The spring was also modelled separately, and not homogenised with the other hose layers (see mesh details as depicted in Figure 6). The simplified (homogenised) model resulted in a number of elements and nodes totalling 45,953 and 147,221, respectively, while the separated spring resulted in 37,375 elements and 231,747 nodes, as seen in Tables 4 and 5.

Table 4. Mesh statistics on the element/node count for the simplified model.

\begin{tabular}{ccc}
\hline Model & Elements & Nodes \\
\hline Simplified model & 45,953 & 147,221 \\
\hline Steel helix & 37,375 & 231,747 \\
\hline
\end{tabular}


Table 5. Mesh sizing details as applied for each layer of the reeling hose.

\begin{tabular}{cccc}
\hline Layer & Mesh Size (m) & Elements & Nodes \\
\hline Liner & $5 \times 10^{-2}$ & 5665 & 11,684 \\
\hline Main ply 1 & $5 \times 10^{-2}$ & 6755 & 13,844 \\
\hline Main ply 2 & $5 \times 10^{-2}$ & 6902 & 14,112 \\
\hline Main ply 3 & $5 \times 10^{-2}$ & 7017 & 14,382 \\
\hline Main ply 4 & $5 \times 10^{-2}$ & 7060 & 14,441 \\
\hline Main ply 5 & $5 \times 10^{-2}$ & 7047 & 14,414 \\
\hline Main ply 6 & $5 \times 10^{-2}$ & 7235 & 14,802 \\
\hline Main ply 7 & $5 \times 10^{-2}$ & 6789 & 13,899 \\
\hline Main ply 8 & $5 \times 10^{-2}$ & 11,005 & 22,581 \\
\hline Filler 1 & $5 \times 10^{-2}$ & 759 & 5478 \\
\hline Helix & 0.5 & 37,380 & 231,778 \\
\hline Filler 2 & $5 \times 10^{-2}$ & 805 & 5810 \\
\hline Holding ply 1 & $5 \times 10^{-2}$ & 7511 & 15,378 \\
\hline Holding ply 2 & $5 \times 10^{-2}$ & 7132 & 14,620 \\
\hline Subcover & $5 \times 10^{-2}$ & 7689 & 68,7670 \\
\hline Breaker 1 & $5 \times 10^{-2}$ & 30,136 & 61,362 \\
\hline Breaker 2 & $5 \times 10^{-2}$ & 33,732 &
\end{tabular}

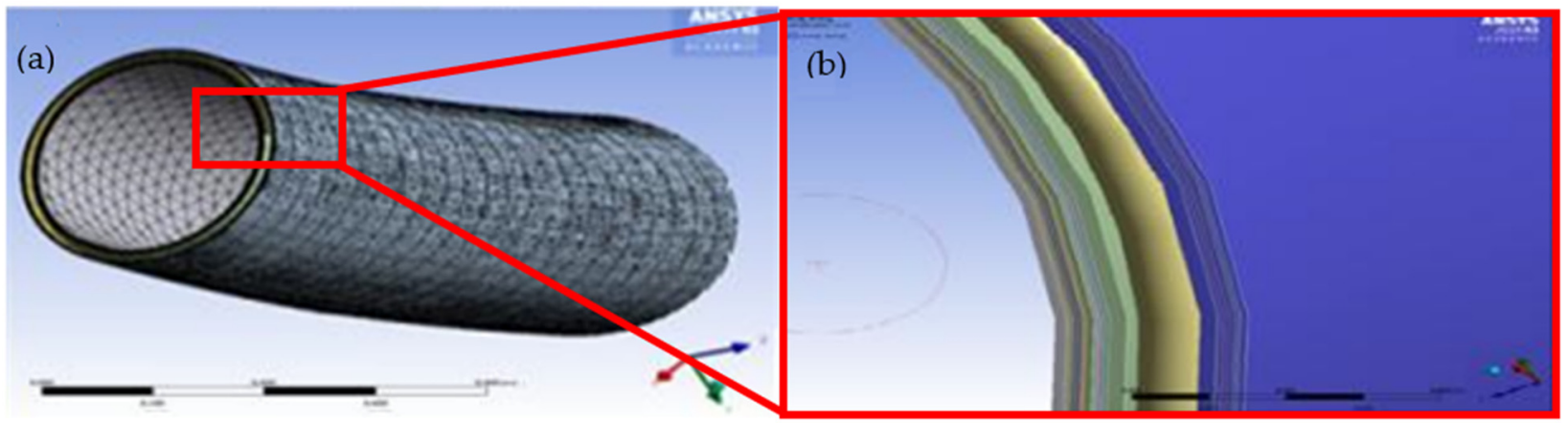

Figure 6. Mesh model of the marine hose in ANSYS Structural R2019, showing (a) the full hose model and (b) its close-up section view with details of layers and helix reinforcement.

\subsection{Boundary Conditions}

Depending on the operation, several boundary conditions were evaluated. Fixed ends were considered for the pressure loading scenarios, but when torsional motions were generated, one end of the hose was fixed while the other end was sealed, meaning bursts with end effects as the loads were induced at one end that was set free. The fixed supports were attached to all faces at the hose line's fixed ends, securing it in place. At the end of the spring, the reinforcement helix was also fixed.

\subsection{Design Load Conditions}

The local design of this maritime hose model adhered to industry design guidelines for bonded hose lines [80-83]. As shown in Table 6, the following loading conditions were used to represent burst, collapse and crush loads. The simplified model was used to calculate total deformation, shear stress, equivalent stress and elastic strain. During operation, the 
hose construction is subjected to both internal and exterior pressures. External pressures are caused by the dynamics of the wave motion that surrounds the hose, as well as variable hydrostatic forces that vary with depth. While the (un)loading hose is used to transfer fluid, the hose must also function under substantial internal pressure to convey the intended fluid. Internal fluids can be gaseous or liquid, and their viscosity can vary. To transfer the fluid inside the hose, an increase in operational internal pressure is required. The pressure inside the hose increases as the viscosity increases. As per the design, an initial operating pressure of 9 bar was distributed within the inner face under internal pressure, as depicted in Figure 7. A fixed boundary condition was also used at the hose end and at the end of the helical spring reinforcement, as depicted in Figure 8. Additionally, the self-weight of the marine hose was considered by applying a gravitational force on the hose.

Table 6. Design load conditions.

\begin{tabular}{cc}
\hline Design Load & Description of Loading \\
\hline Burst & Internal pressure of $2.0 \mathrm{MPa}, 3.5 \mathrm{MPa}$ and $5 \mathrm{MPa}$ \\
\hline Collapse & External pressure of $4.5 \times 10^{5} \mathrm{~Pa}, 7 \times 10^{5} \mathrm{~Pa}, 9.5 \times 10^{5} \mathrm{~Pa}, 1.26 \times 10^{6} \mathrm{~Pa}$ \\
\hline Crush Load & External crushing pressure applied, of magnitude $1.25 \times 10^{7} \mathrm{~Pa}$ \\
\hline
\end{tabular}

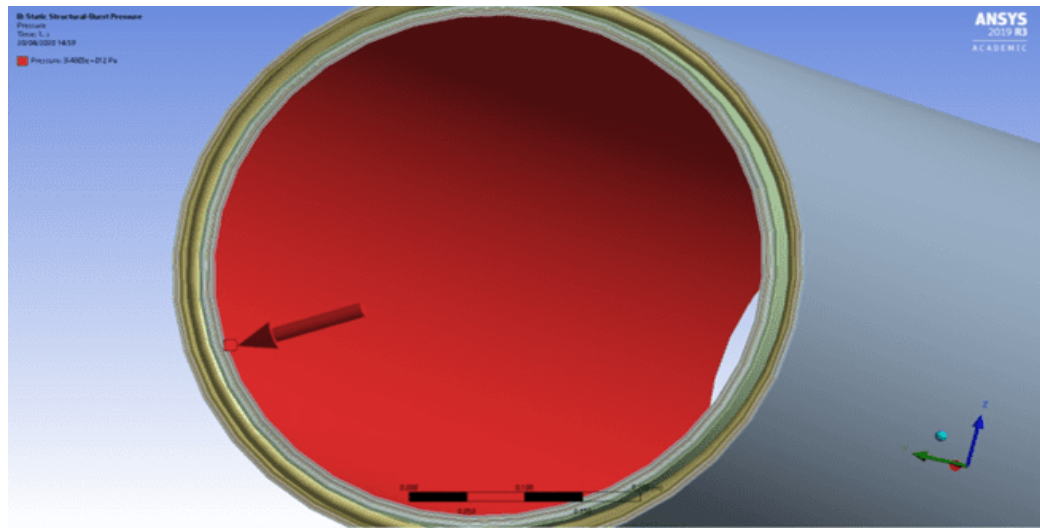

Figure 7. Internal pressure load applied on the offshore hose in ANSYS Static Structural 2019 R3.

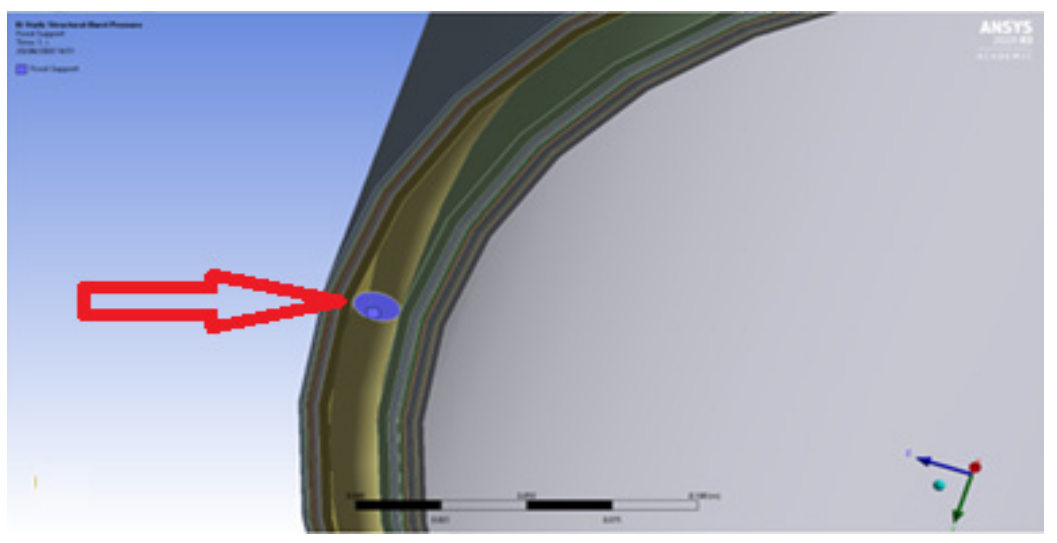

Figure 8. Fixed boundary condition showing end of helical spring of the marine hose in ANSYS Static Structural 2019 R3. (The arrow points to the location of the fixation, not the load application.)

\subsection{Helix Reinforcement}

This model was made with dimensions that are similar to those used in industrial designs. The model in the present study was created based on the validated model in an earlier study [21]. The helix has a $40 \mathrm{~mm}$ pitch and a diameter of approximately $14.22 \mathrm{~mm}$. 
As previously indicated in this study, the material used in this simulation was steel. Figure 8 shows the model that was used in this investigation. At each end of the helix, $2000 \mathrm{~Pa}$ of external pressure was applied perpendicularly to the faces of the ends of the helix. This was implemented solely to observe the basic mechanical behaviour of the helix when it is compressed uniformly at both ends. Lower pressure was applied to the model in order to observe the trend in the hose's helix. Both ends of the hose segment were loaded. This represents how the hose portion reacts to its own weight or other connected pieces pushing against it. It should be highlighted that the spring simulated in ANSYS can also be implemented using an identical elastic support condition or even a virtual spring, which would have made the model much more efficient. On the other hand, the spring has been modelled fully because the study's goal is to investigate spring behaviour so that spring load and the number of spring layers (one or two helical springs) can be considered in the model's conceptualisation. Other methods of numerical models for spring models exist in the literature [84-86]. The parameters used in constructing the helix geometry considered in the numerical model are listed in Table 7. See Appendix A for helix spring's analytical modelling, which is also detailed in related literature [21].

Table 7. Particulars for helix reinforcement and marine bonded composite hose (MBCH) models.

\begin{tabular}{cc}
\hline Particulars & Quantity \\
\hline Hose nominal inner radius & $250 \mathrm{~mm}$ \\
\hline Outer radius & $294 \mathrm{~mm}$ \\
\hline Length of hose model & $1000 \mathrm{~mm}$ \\
\hline Mean radius of helix reinforcement & $284 \mathrm{~mm}$ \\
\hline Diameter of helix reinforcement coil & $12.7 \mathrm{~mm}$ \\
\hline Pitch of helical reinforcement & $36 \mathrm{~mm}$ \\
\hline Total number of coil turns & $41 \mathrm{turns}$ \\
\hline Width of helix reinforcement & $1200 \mathrm{~mm}$ \\
\hline Height of helix reinforcement & $1500 \mathrm{~mm}$ \\
\hline
\end{tabular}

\section{Results and Analysis}

This section provides a concise and precise description of the numerical results and their interpretation, as well as the discussions that can be drawn.

\subsection{Results of Helix Deformation}

From the result in Figure 9, showing the deformation on the helix layer and the underlying layer, the areas of the offshore bonded composite hose section that experienced the highest deformation magnitudes as a result of the influence of the stresses on the helix layer can be seen. The helical spring has a different material from the layers around it, and as such there are some voids created which may lead to some nonlinearities in bonding. Therefore, the deformation will increase, depending on the areas that experience the highest lateral and vertical forces along the cross-section of the helical spring reinforcement, as seen in Figure 9. This also indicates the extent of the contribution of the helix to the maximum deformation magnitudes experienced at the areas of maximum curvature. From Figure 9a, the magnitude of helix deformation can be observed which, although smaller in value compared to other results displayed, increases toward a maximum at the area of maximum curvature. From Figure 9b, the details of the deformation of the underlying layers surrounded by the reinforcement helix also demonstrated an increase in the magnitudes of deformation at areas toward the maximum curvature. The results show that the helix is constricted by the external pressure, as it will subsequently push against the underlying layers with increased force and, thus, create the areas of increased deformation depicted in Figure 9b. In summary, the area of maximum curvature of the section that experiences 
maximum constriction will increase the stresses in these areas, further demonstrating likely areas of fatigue and possible structural weakening. Thus, the strength of the helix reinforcement can also be increased.
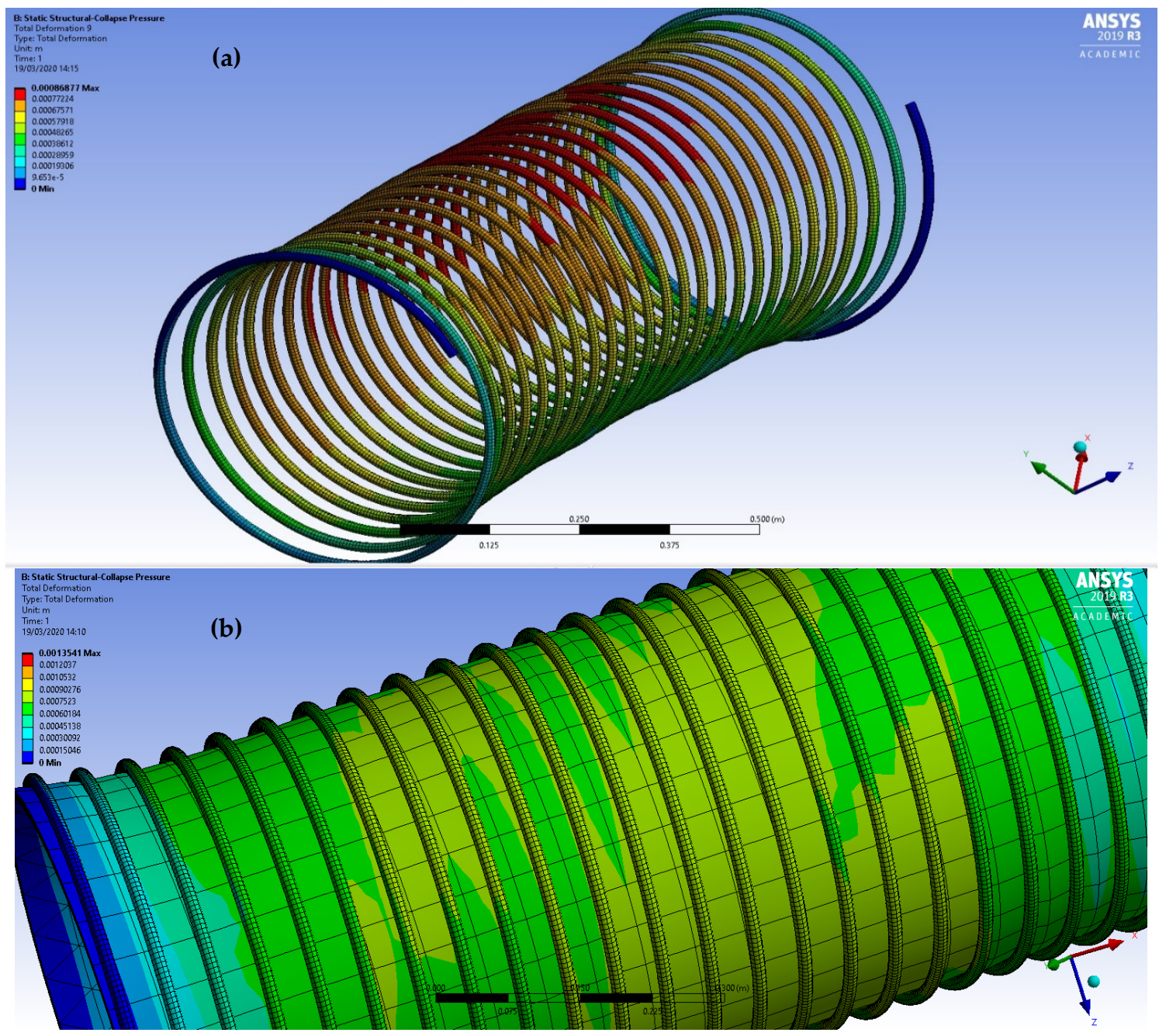

Figure 9. Reinforcement helix's deformation during collapse test, showing (a) helix alone, and (b) helix on the underlying layer.

\subsection{Results of Helix Localised Damage}

Based on the study of the reinforcement helix and its localised damage, a closer inspection of the results for the reinforcement helix regarding the equivalent stress presents some interesting observations. Due to the increased external pressure, in the collapsing case, it was noted that along the structure of the helix were multiple small sites of visual localised damage. These crinkles demonstrate areas of significant stress concentration once deformed and, therefore, highlighting these areas as critical in contributing to the potential failure of the reinforcement layer. These results will be discussed in further detail in Section 4.7. Typical numerical models on springs show that they have failure behaviour under dynamic transient loads $[85,86]$. As seen on Figure 10, there are different locations of the damages to the helical spring reinforcement, which the authors identified as "damage sites". Similar fatigue studies on helix reinforcement include composite cords [76], as microcracks are seen in the composite materials [87], meaning the helix damage observed here is novel. From Figure 10, it is evident that the stress profile along the damage sites is highest. Additionally, Figure 10 demonstrates stress concentration on the nodes of a coarse mesh. Buckling should be visible on explicit simulations, with further studies recommended to 
confirm the damage that has been implied. Further analysis is also recommended on the fatigue of the reinforcement to ascertain the full extent of the damage that comes from the spring reinforcement.

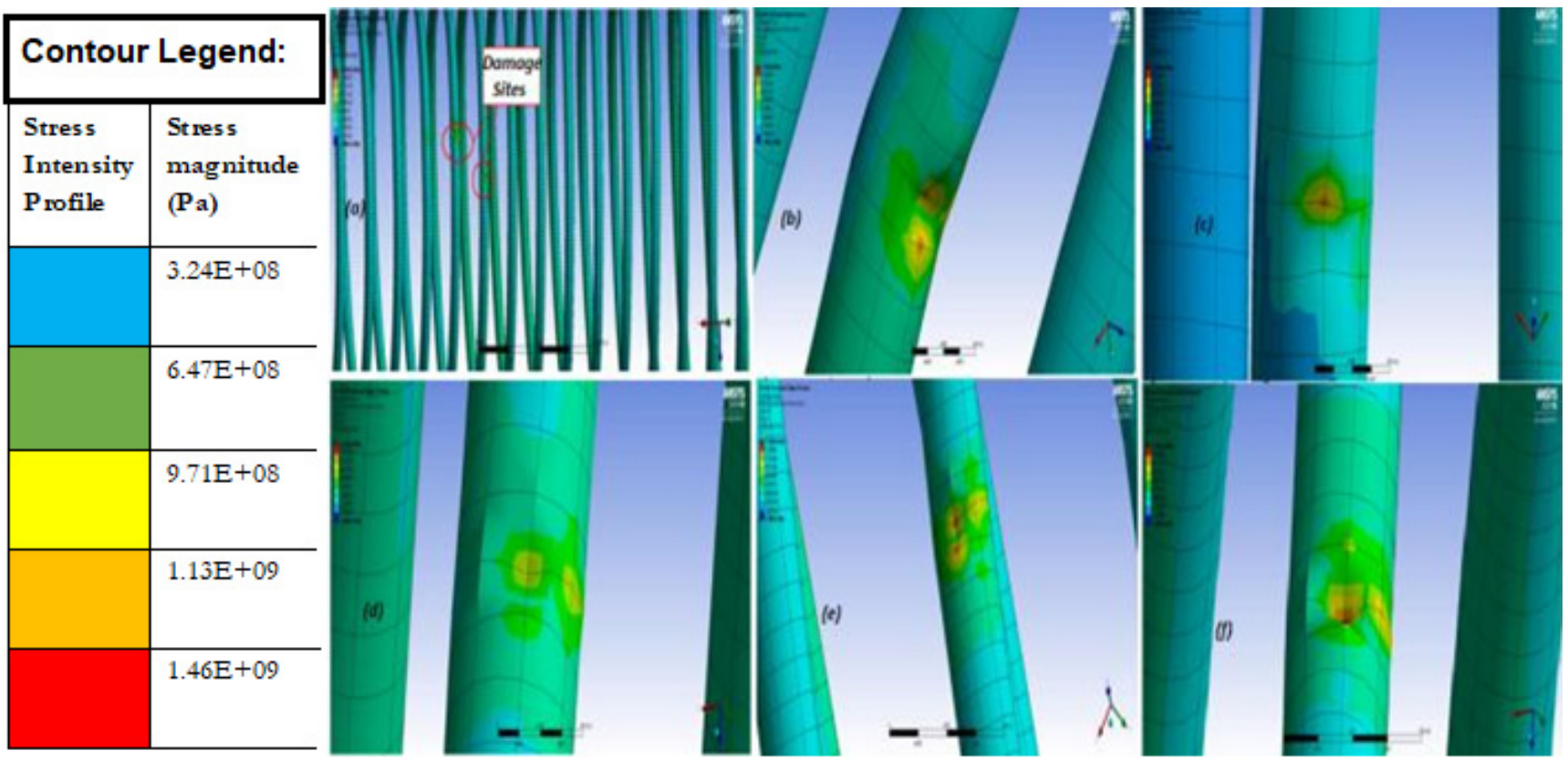

Figure 10. Reinforcement helix's deformation under extreme conditions showing (a) damage sites along different locations on the helix, (b) damage site 1, (c) damage site 2, (d) damage site 3, (e) damage site 4 , (f) damage site 5 . All these images (b-f) present the stress intensity magnitudes on contour profiles where damage/failure spots and deformations were spotted.

The assessment of the helix under burst and collapse loads shows some interesting mechanical behaviour. The results in Figures 11-13 show that the reinforcement layer, particularly, would have certain areas that will likely have earlier fatigue. This are considered for different loadings, and it shows that the extreme loadings could lead to structural failure, thus requiring more reinforcements at such ends. For hoses that will be reeled, it is recommended that here are double helical reinforcements to ensure that the structure withstands the required loads. The resulting profile also indicates locations on the helix that could develop possible high deformations, but this requires further postprocessing. It is recommended that there should be more reinforcement along the locations of these primary areas of delamination from the filler layer surrounding the reinforcement.

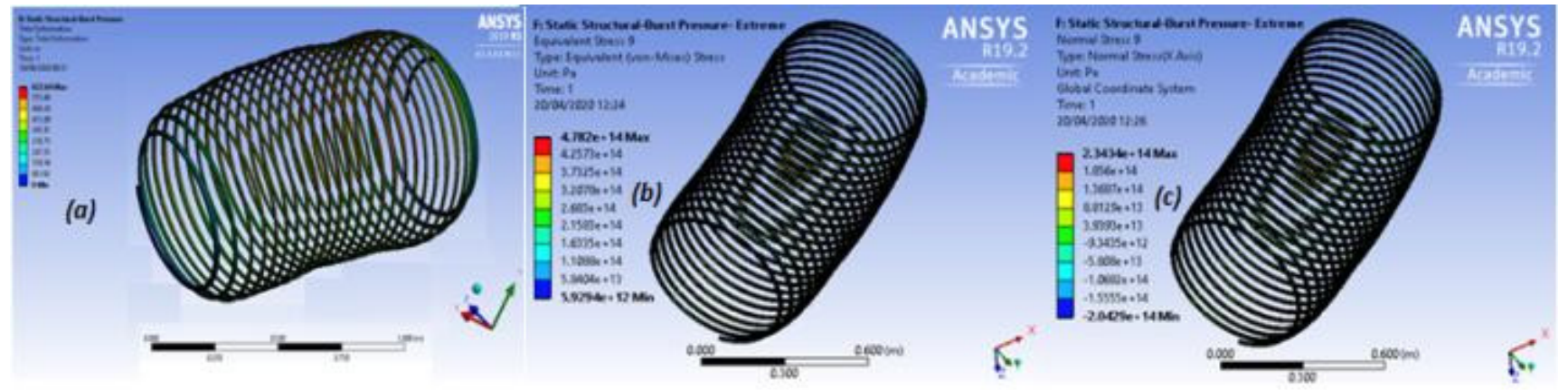

Figure 11. Burst loading on the helical spring reinforcement under extreme conditions showing (a) total deformation, (b) equivalent von Mises stress and (c) normal stress (ends are free without end fittings in this case). 

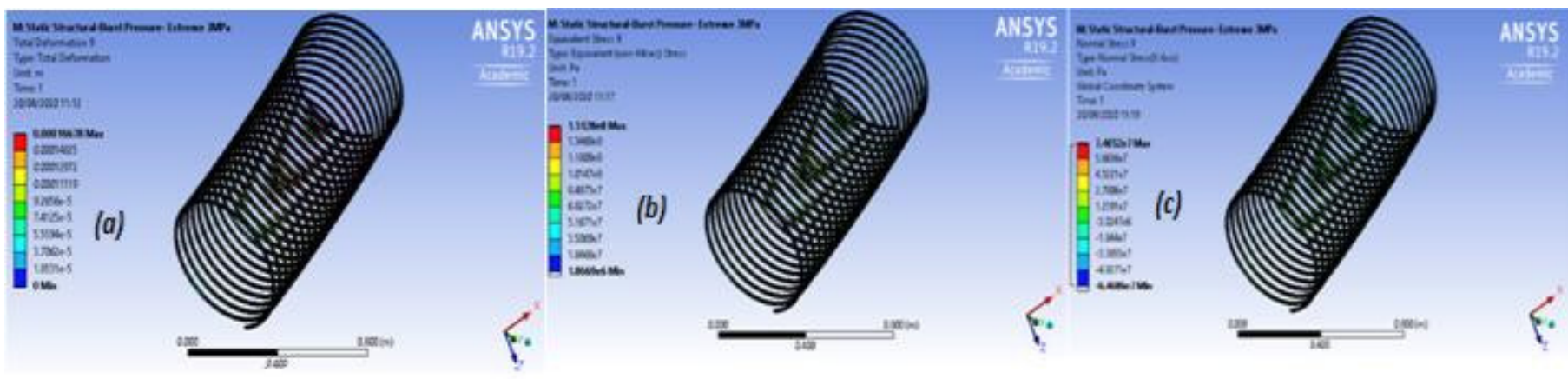

Figure 12. Burst loading on the helical spring reinforcement under operational conditions showing (a) total deformation, (b) equivalent von Mises stress and (c) normal stress (ends are free without end fittings in this case).

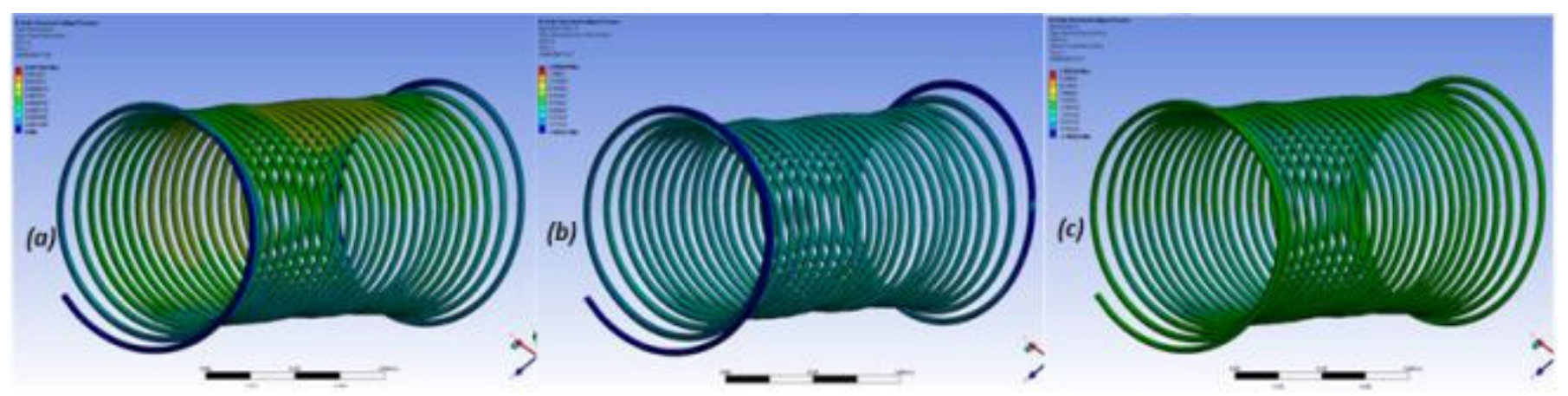

Figure 13. Collapse loading on the helical spring reinforcement under extreme conditions showing (a) total deformation, (b) equivalent von Mises stress and (c) normal stress (ends are free without end fittings in this case).

\subsection{Results of Factor of Safety (F.S)}

The above results show that the reinforcement helix does indeed experience localised damage due to the external crushing pressure applied, of magnitude $1.25 \times 10^{7} \mathrm{~Pa}$. An analysis of the stress distribution on the helix structure was carried out to assess the safety factor of the helix. It is important to note that any calculation resulting in a Factor of Safety (F.S) of below 1 is deemed unsafe. Optimally, the value of the F.S should be 2 or above. The general equation used in calculating the F.S is expressed as Equation (1):

$$
\text { Factor of Safety }(\text { F.S })=\frac{\text { Material allowable stress }}{\text { Actual applied stress }}
$$

In Figure 14, the Factor of Safety was analysed using the stress tools given in ANSYS Structural version 2020 R2. It was configured to calculate the Factor of Safety for both steel layers of the model, the inner liner and the reinforcement helix. Additionally, for one of the composite layers, the layer chosen was one of the holding plies made from glass-reinforced nylon. For the material properties of the steel and nylon composites, please refer to Tables 2 and 3. The detailed discussion of these results has been presented in Section 4.7. 


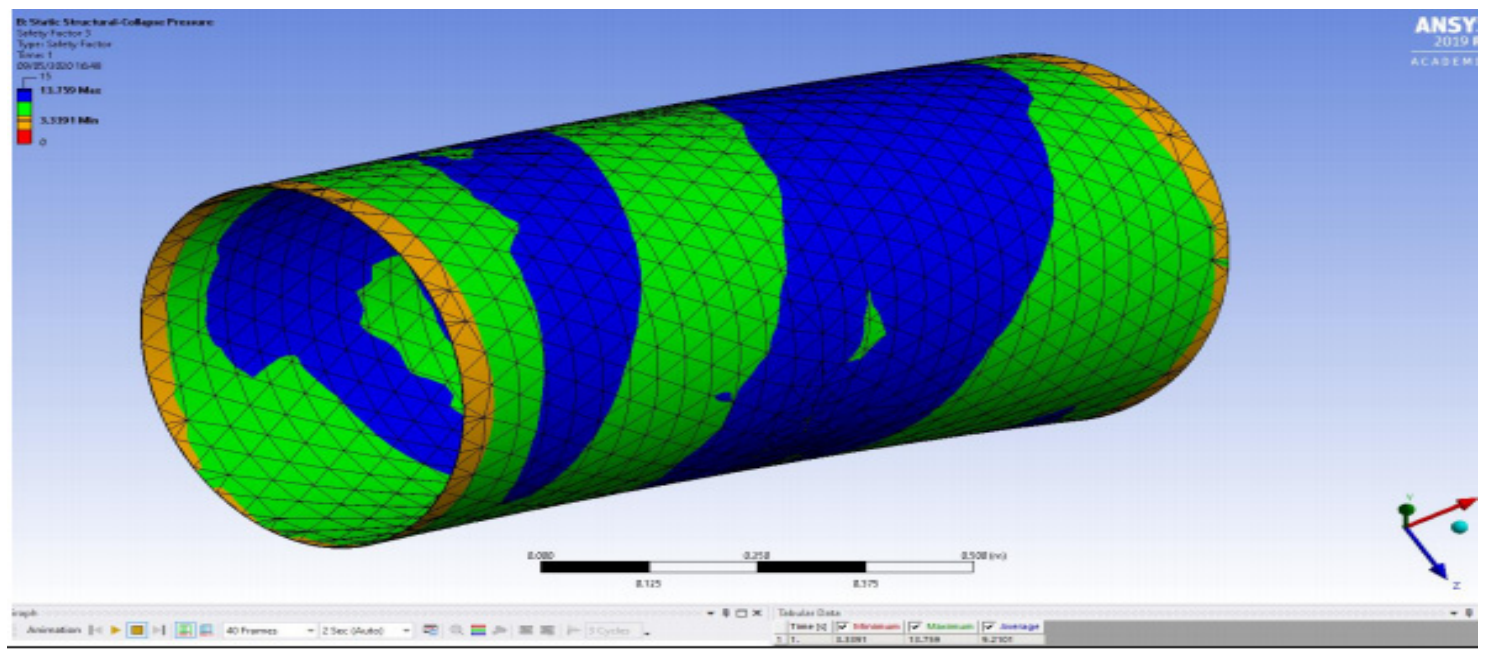

(a)

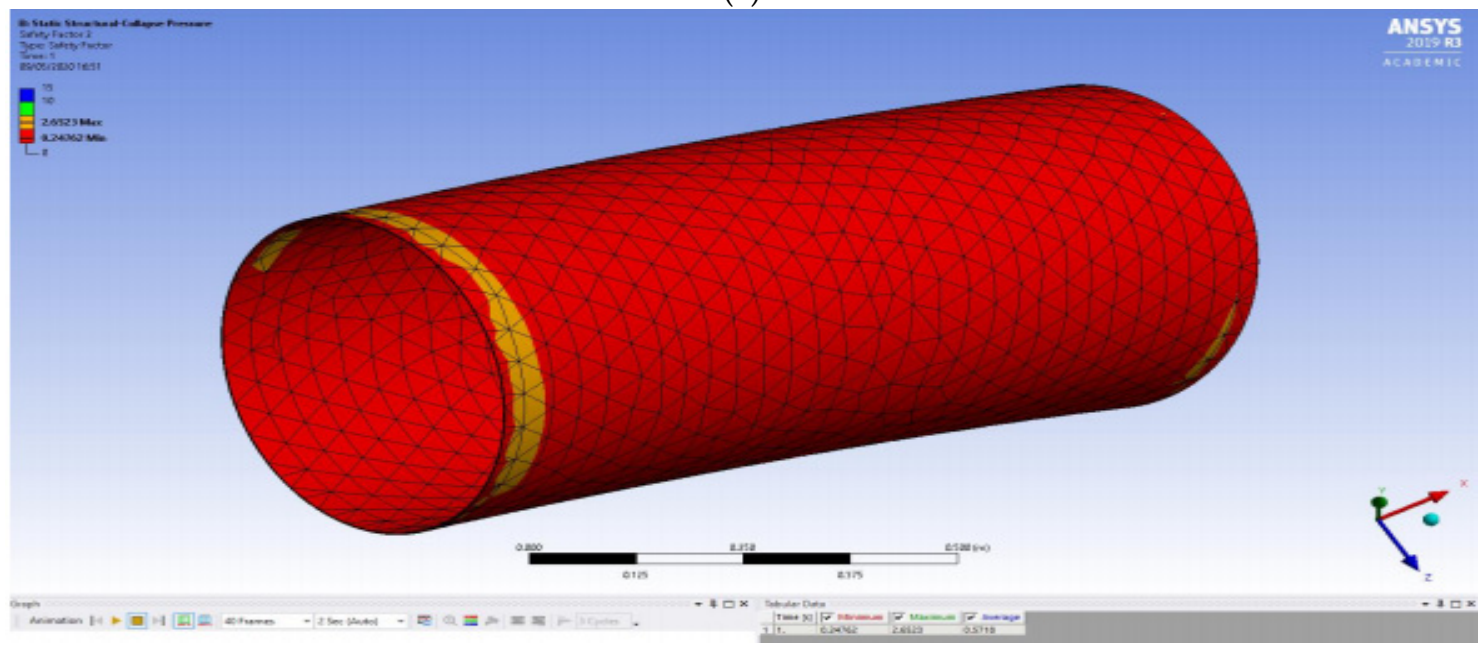

(b)

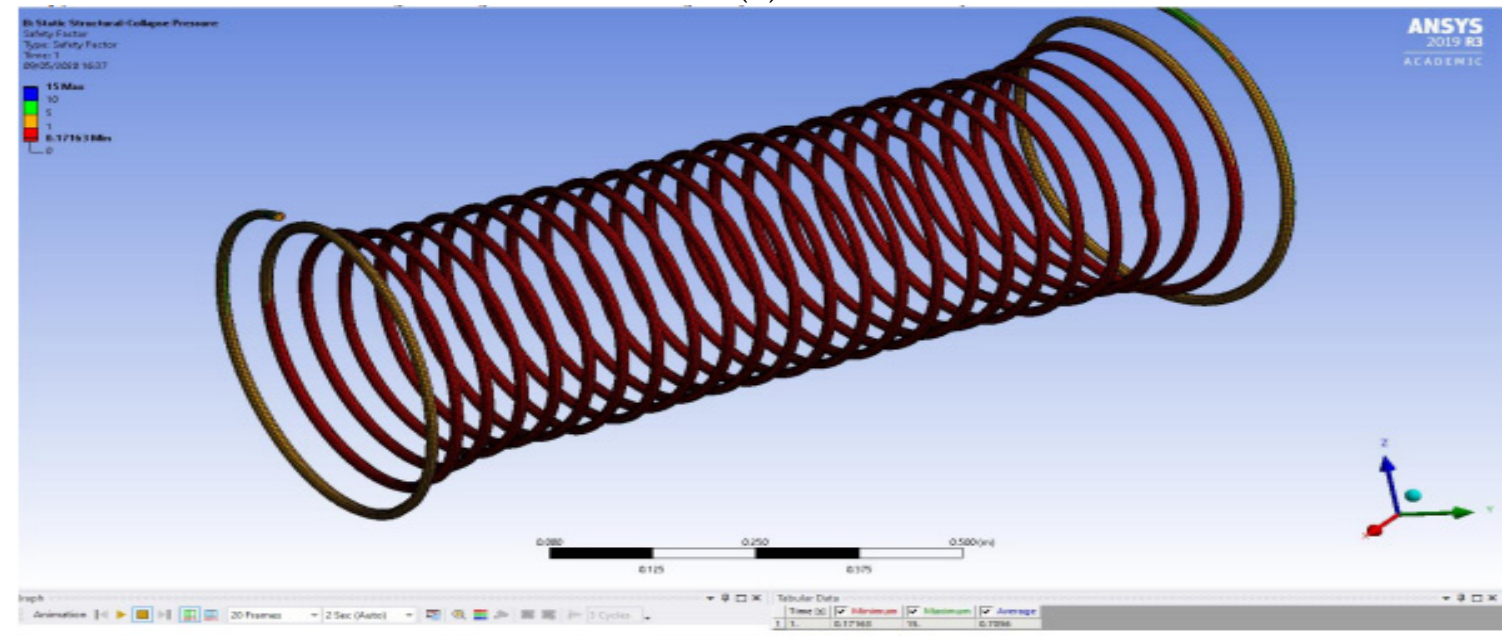

(c)

Figure 14. Factor of Safety analysis of (a) holding ply (glass fibre-reinforced nylon 6/6), (b) inner liner (structural steel), and (c) helix layer (structural steel) using load case without end fitting.

\subsection{Results of Hose's Liner Wrinkling}

Liner wrinkling is a phenomenon that has been observed in pipelines, and was also seen in this offshore bonded composite hose model during the burst test. Due to the extreme internal pressure applied during the model test, the material starts to wrinkle at 
the external liner, as seen in Figures 15-18. Liner wrinkling is evident in Figure 15; however, less wrinkling is found in other layers in Figure 16. As seen in Figures 17 and 18, the pressure loads have an impact on the walls of each layer differently. It can be observed that the ends that had been fixed have high deformations. As such, it is recommended that highly reinforced ends be used at such ends to offset the high collapse pressure. In addition, the body of the offshore bonded composite hose along the arc length also has liner wrinkling, similar to those seen for the burst cases. The liner wrinkling is an indication that the liner material may be compromised, or that the metal-composite interface between the liner and the composite material is weakened. Even in bonded contacts, there is still a high prevalence of micro-strains [87] and micro-cracks [88]. Thus, there might be micro-cracks resulting from the liner wrinkling. Thus, the designer is required to increase the bonding friction coefficient in this layer, increase the thickness of the liner and use liner materials with higher strength. Liner wrinkling is also observed under external pressure loading.

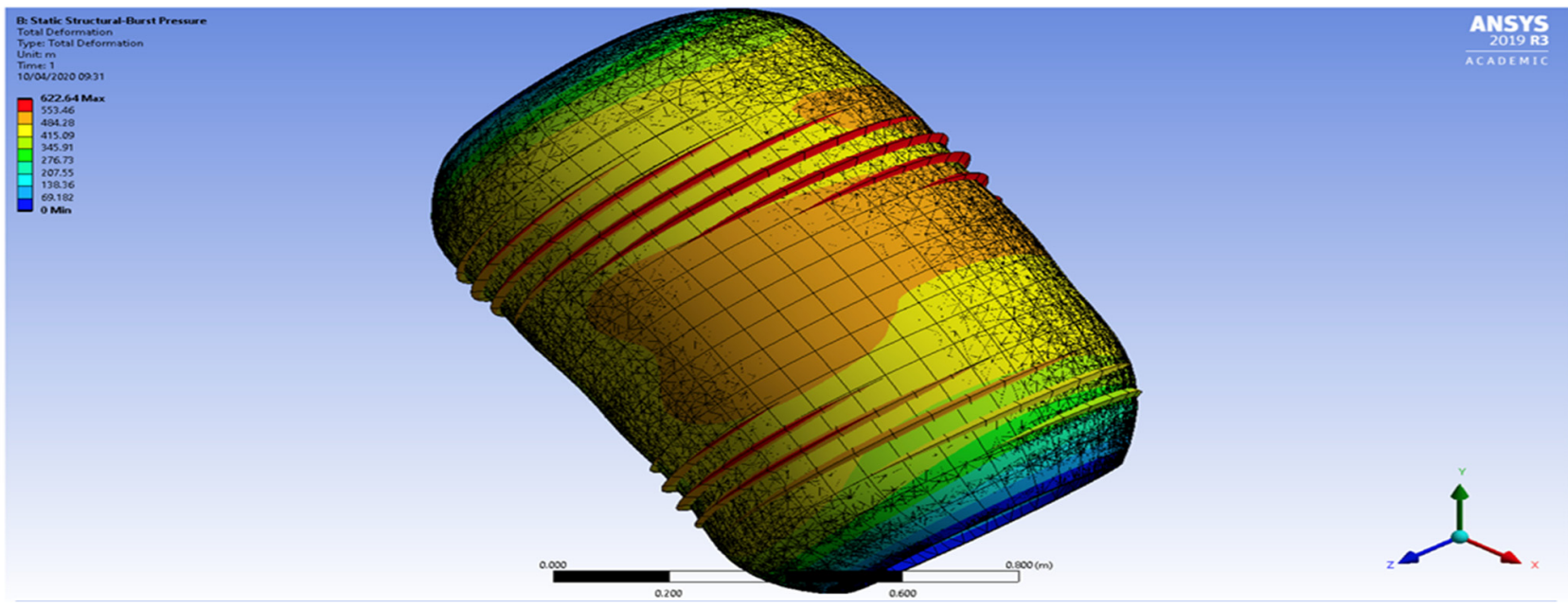

Figure 15. Liner wrinkling of different layers during extreme burst load for total deformation.

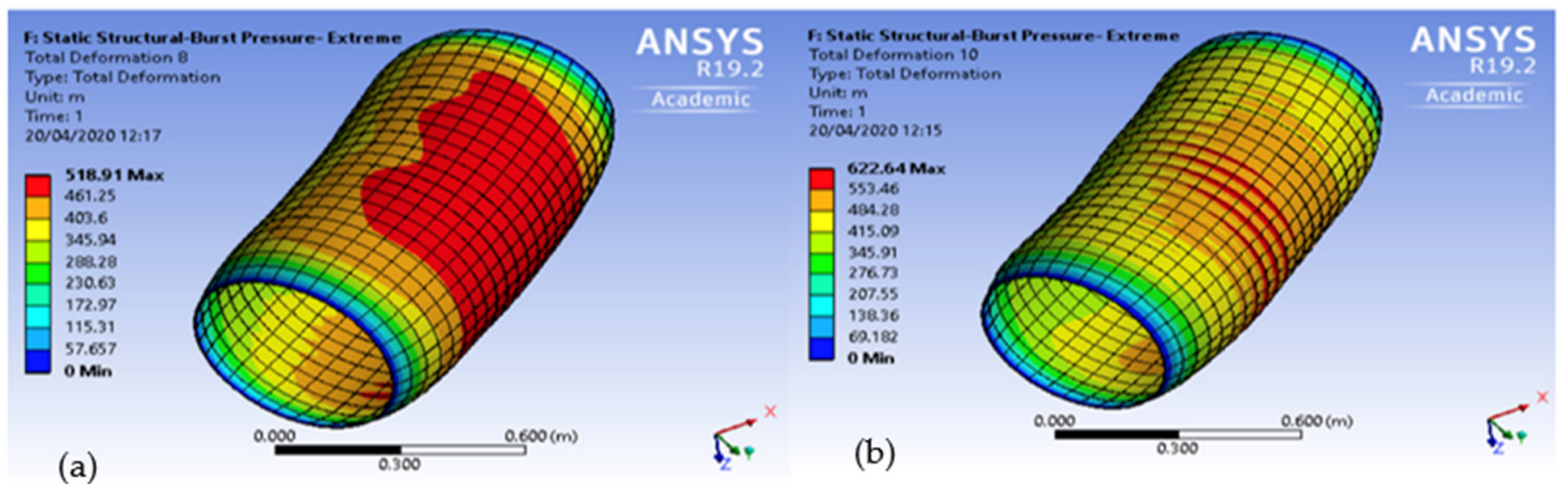

Figure 16. Layer wrinkling of different layers during extreme burst load for total deformation, for (a) Layer 8 and (b) Layer 10. 


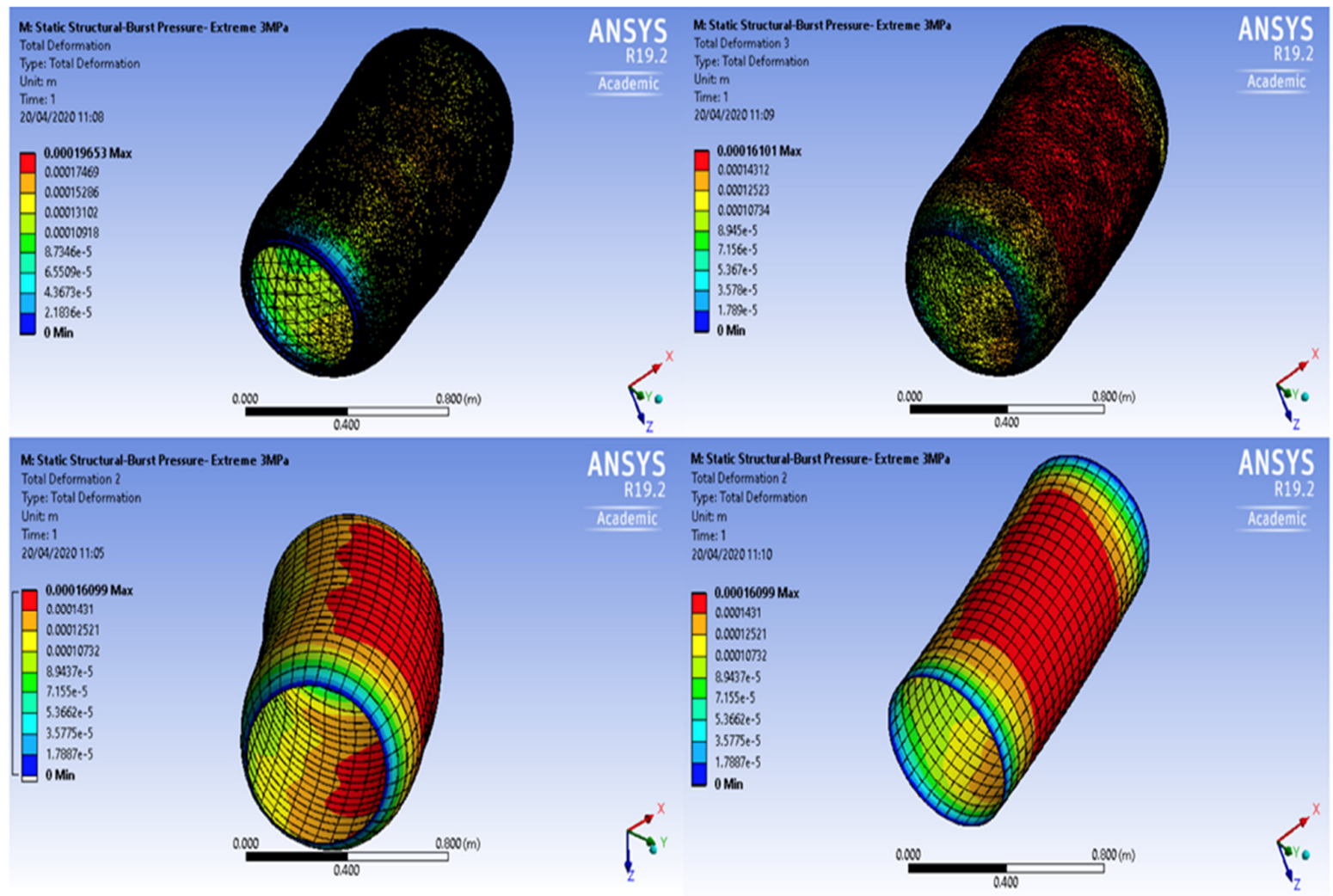

Figure 17. Burst loading of different layers under operational conditions for total deformation without wrinkling, for four different layers of the marine hose.
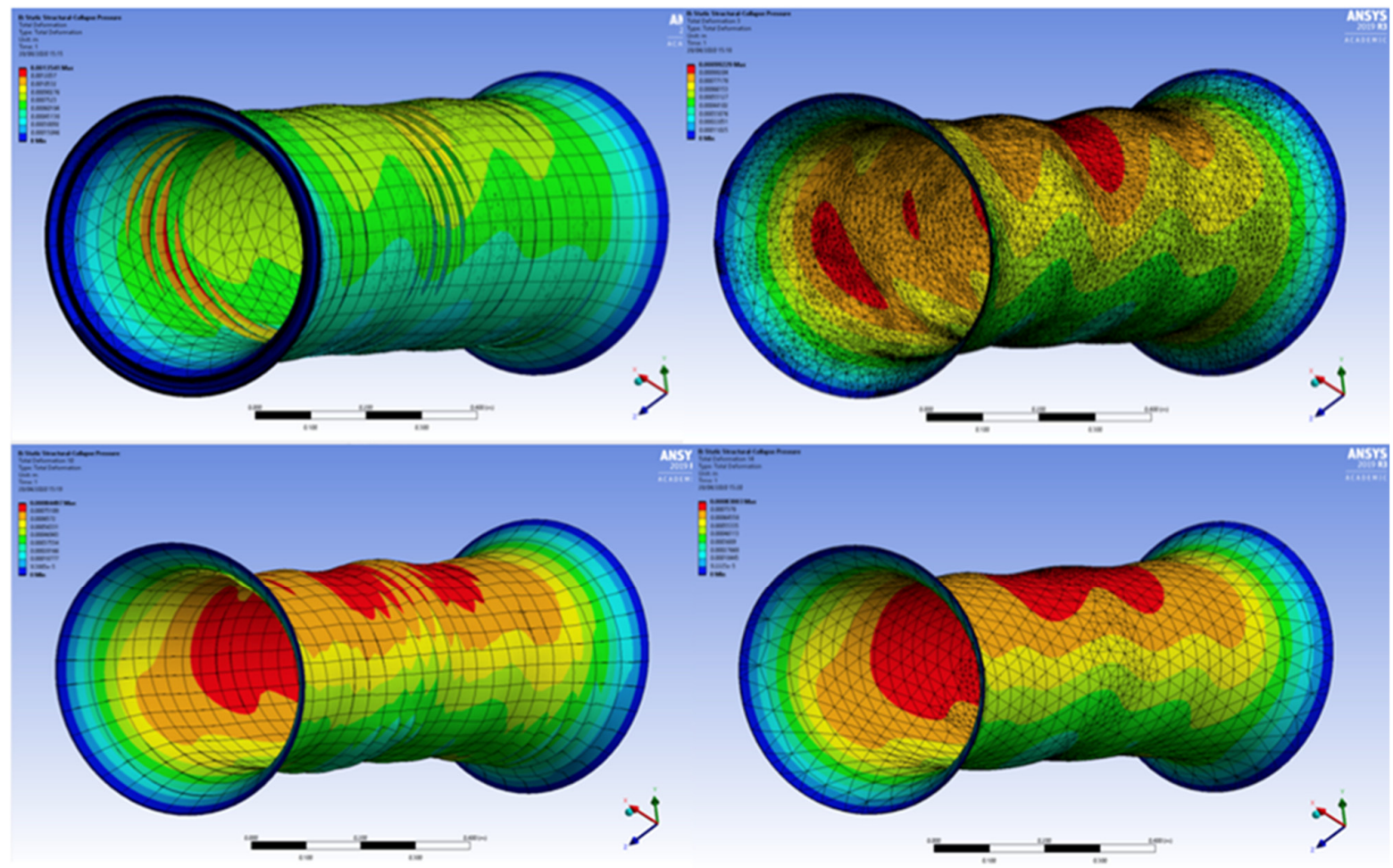

Figure 18. Collapse loading of different layers under extreme conditions, for total deformation on 4 different layers of the marine hose (under $0.5 \times$ magnification, and the ends are without end fitting or additional reinforced ends). 


\subsection{Results of Hose Collapse Load}

The mechanical behaviour of the marine hose was also investigated to visualise and predict the characteristics under collapse load. Using the same ANSYS simulation for the local design of the marine hose, the results presented in Figures 18-20 were obtained. They represent the total deformation, equivalent stress and normal stress, respectively. These results demonstrate mechanical behaviour under standard operational pressure rating of 9 bar. From Figure 18, it can be observed that maximum deformation occurred around the mid-sections of the marine hose under collapse. At that mid-section, the point of maximum curvature can be obtained when postprocessed. From this study, it can also be seen that the deformation profile for the four layers are distributed differently, but in a similar pattern. Hence, the outermost layer experiences the highest collapse pressure load, rather than the innermost layer. However, this multi-layered composite hose is designed to withstand high temperatures and high pressures. Therefore, it is recommended that the outer liner material of any marine hose must have good resistance to collapse pressure. In Figure 19, the von Mises stress distributions are different for each layer type. This implies that the hose requires thicker external liner material. Additionally, such locations need to have thicker layers or an increase in the coefficient of friction within the bonding contact. It can also be observed that the ends that had been fixed have high stress profiles, as seen in Figures 19 and 20. As such, it is recommended that highly reinforced ends be used at such ends to offset the high collapse pressure. In addition, the body of the offshore bonded composite hose along the arc length also have liner wrinkling observed, similar to those seen for the burst cases.
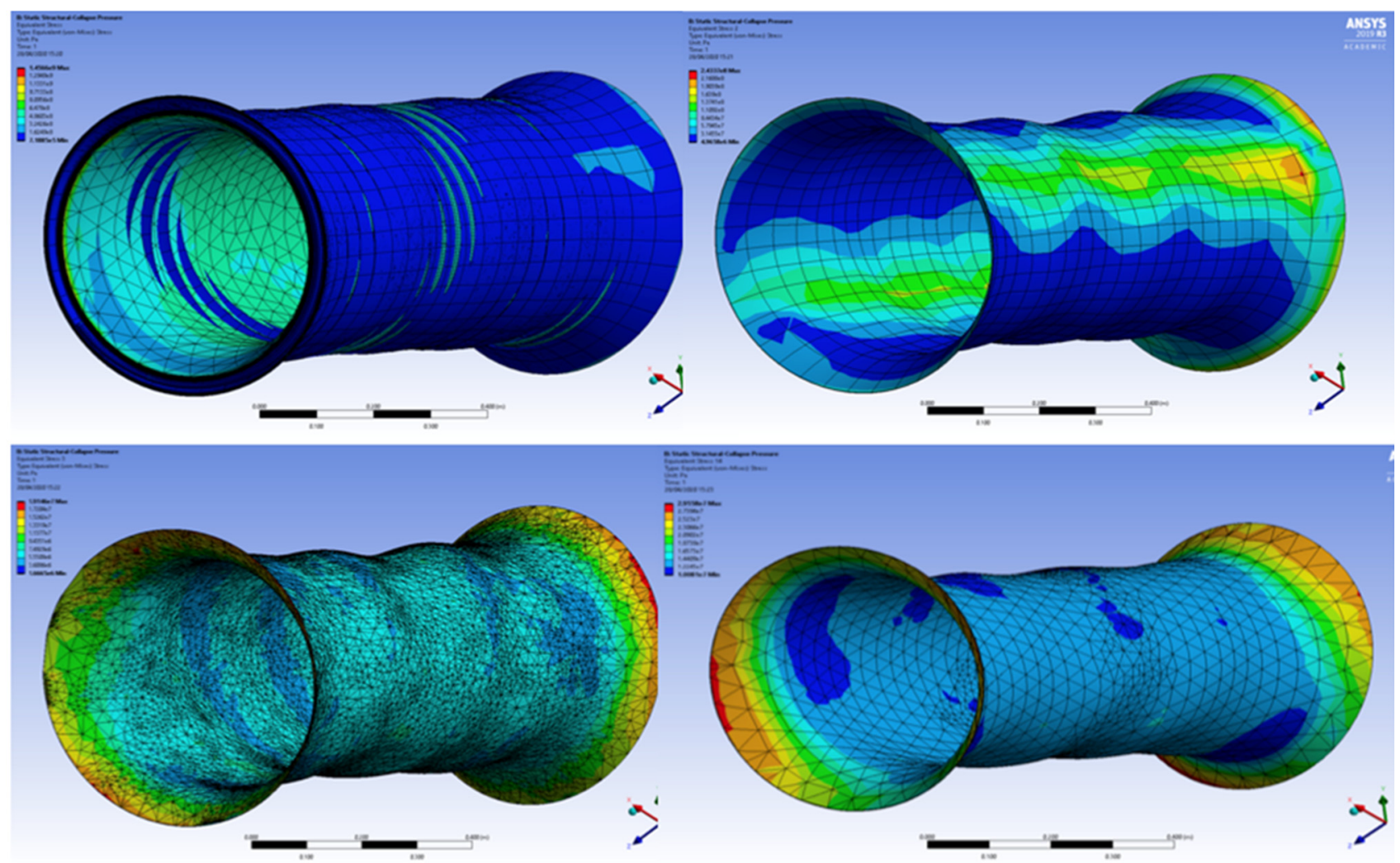

Figure 19. Collapse loading of different layers under extreme conditions, for equivalent von Mises stress on 4 different layers of the marine hose (under $0.5 \times$ magnification, and the ends are without end fitting or additional reinforced ends). 


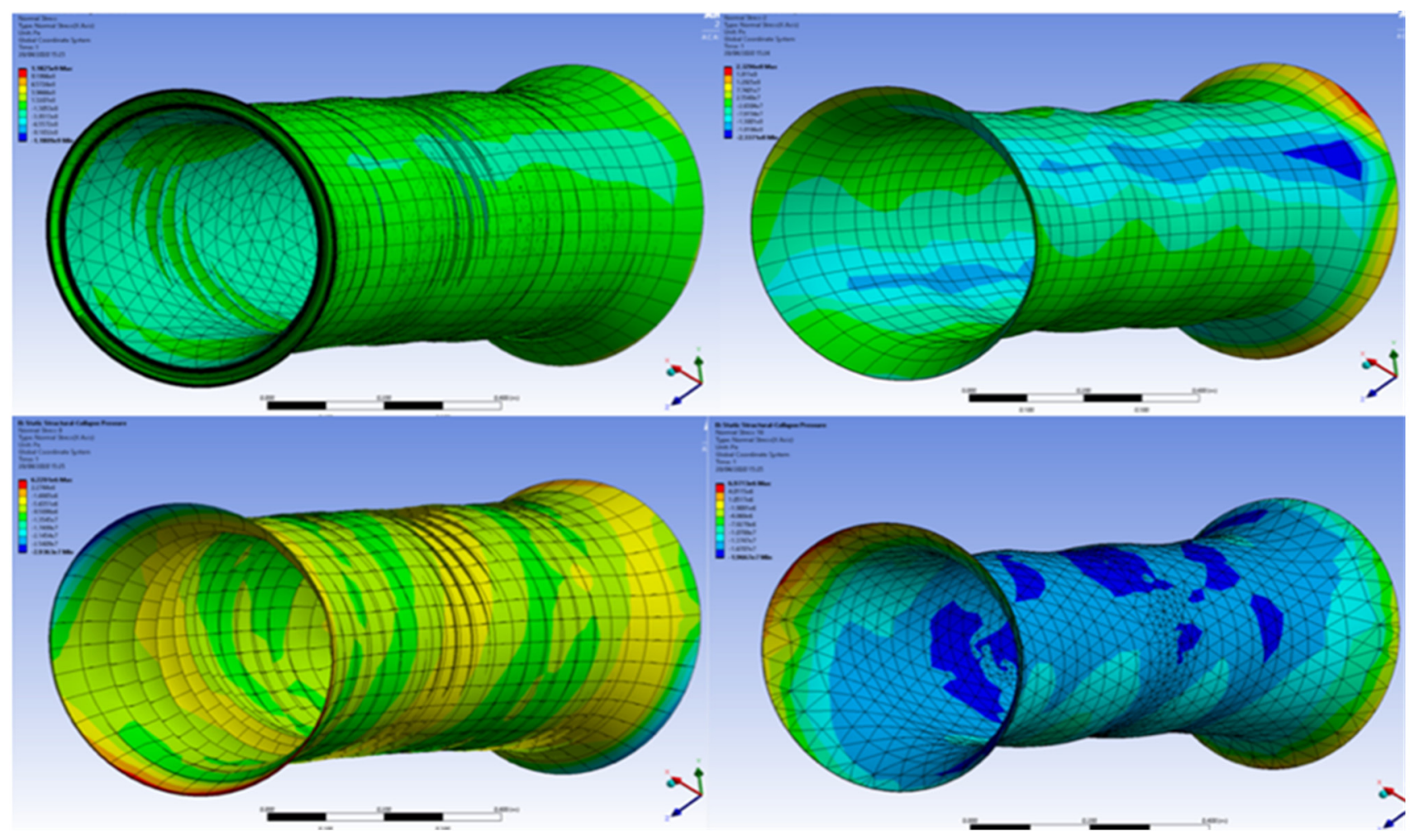

Figure 20. Collapse loading of different layers under extreme conditions, for normal stress on 4 different layers of the marine hose (under $0.5 \times$ magnification, and the ends are without end fitting or additional reinforced ends).

\subsection{Results of Hose Ovalisation}

For the local design of the offshore hose, we used a simplified model that was designed through ovalisation, and the results of total deformation, shear stress and equivalent stress are presented in Figure 21. These results demonstrate the mechanical behaviour under standard operational pressure. For this instance, the hose was operating under the pressure rating of 9 bar. It can be demonstrated that maximum deformation occurs at the point of maximum curvature of the pipeline. Although the value of deformation, being a maximum value of $0.00875 \mathrm{~m}$, can be shown to be a significantly small value, the results still demonstrate that maximum deformation occurs in the region of maximum curvature. Therefore, it can be implied that this is the region of the offshore bonded composite hose structure that is most likely to fail initially due to an increase in unregulated internal pressure. This would agree with previous literature and the results observed from controlled burst pressure tests, resulting in an opening mode fracture of the pipeline followed by fracture propagation from its external layers; this will be discussed in further detail later. It can be demonstrated that equivalent stress is minimal on the external layers of the pipeline, with maximum values of equivalent stress of around $6.0019 \times 10^{8} \mathrm{~Pa}$, being concentrated at the inner liner of the pipeline. The liner is the first layer that will experience maximum force per unit area; therefore, suitable material must be selected with high strength to contain the product fluid being transported. In the model, structural steel was chosen for the initial simulation based upon previous literature; however, this would be an area for further investigation with different materials that could prove to be the more optimal choice to deal with high stress values. Shear stress results also follow a similar trend to the equivalent stress, with maximum stress values being concentrated at the inner liner layer. The only differing factor with the shear stress result is that the maximum stress is concentrated at the areas of maximum curvature on the upper surface of the liner, in a similar fashion to the deformation severity distribution. A common result that can be 
concluded from the initial results is that the areas that are most at risk are the areas of maximum curvature of the pipeline. The reeled state of the pipeline introduces enhanced mechanical stress and deformation results due to the pipeline being bent over the reeling drum.

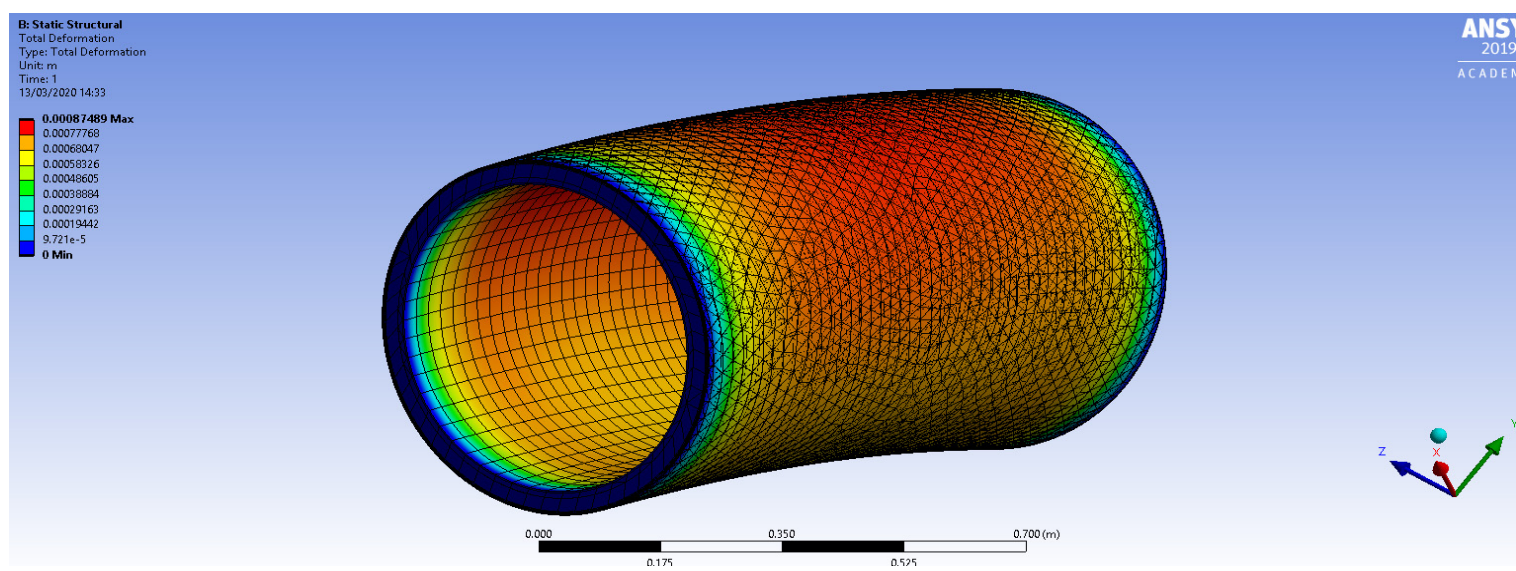

(a)

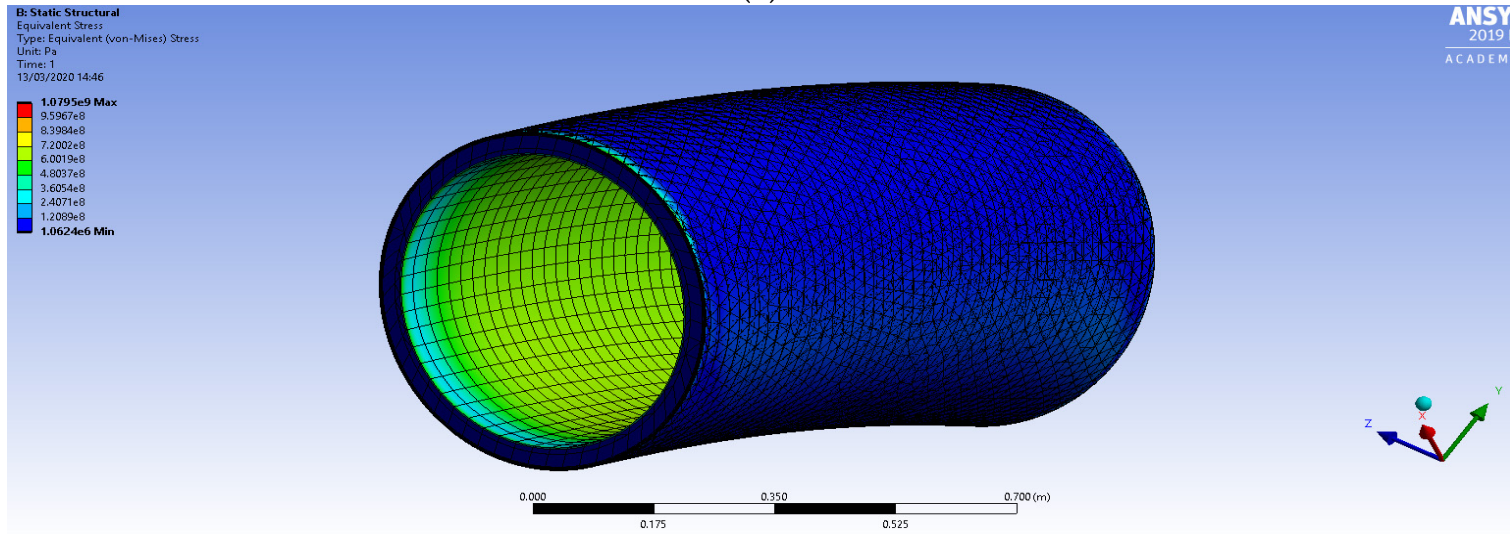

(b)

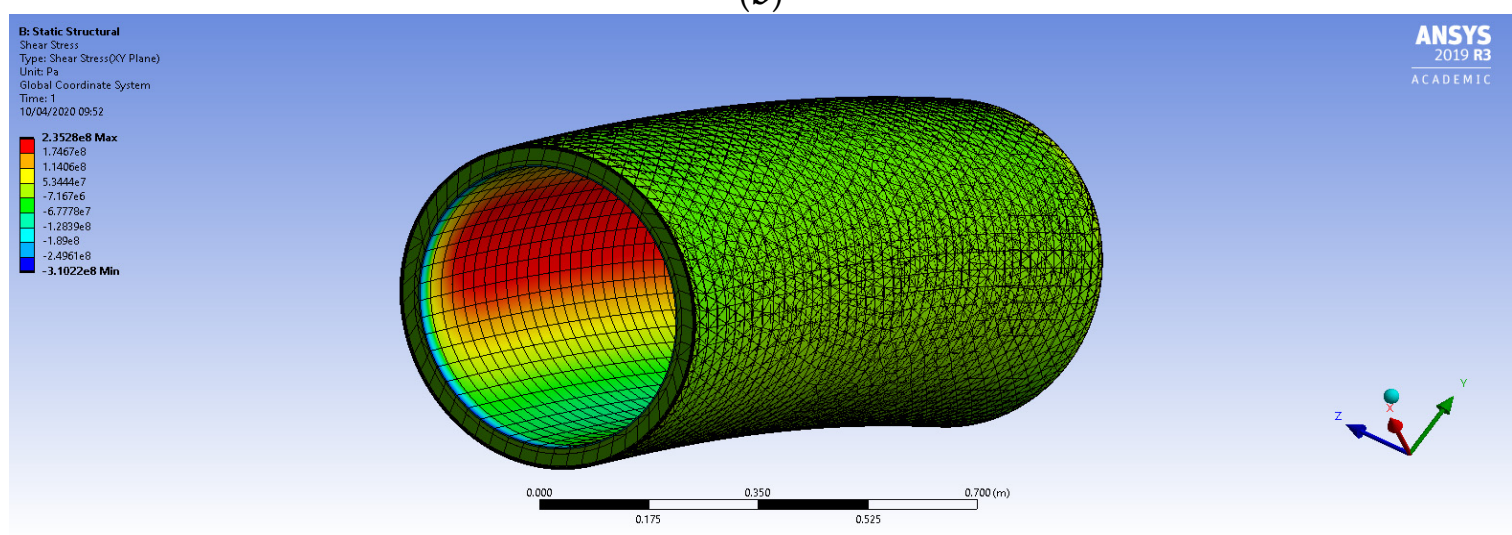

(c)

Figure 21. Simplified model of the offshore bonded composite hose for (a) total deformation, (b) equivalent stress and (c) shear stress.

\subsection{Discussion of Results}

The results in Sections 4.1-4.6 indicate the helix's contribution to the maximum deformation magnitudes experienced at the areas of maximum curvature. From the first image of further helix deformation, it can be shown that the magnitude of deformation, although smaller in value compared to other results displayed, increases toward a maximum at the 
area of maximum curvature. Further, the second image details the deformation of the lower layers surrounded by the reinforcement helix, demonstrating increased magnitudes of deformation at areas toward the maximum curvature also. The results of the first image can explain the results of the second, for as the helix is constricted from the external pressure, it will push against the lower layers with increased force and, therefore, create the areas of increased deformation depicted in the second image. The area of maximum curvature of the section will experience maximum constriction and, therefore, increase stresses in these areas, further demonstrating likely areas of fatigue and possible structural weakening. However, it should be noted that the magnitudes of deformation for the helix are relatively small, and this could be due to the filling layers surrounding the helix providing some element of cushioning from both bursting and collapsing pressures. Most interestingly, however, upon closer examination of the collapse case of the reinforcement helix, the results of equivalent stress yielded notable observations. Throughout the helix structure, it was observed that there were small areas of visual damage, randomly distributed along the helix structure. These sites demonstrated small crinkling of the helix material under the external pressure. From this crinkling, it could be observed that the equivalent stress was concentrated toward maximum magnitudes at the centres of these damage sites. Localised inward deformation of the material produces small 'concentrated points' on the structure, and these points act as stress concentrators and allow for significant stress build-up at these points, therefore producing extreme potential for crack propagation and, finally, failure. These damage sites were numerous and demonstrate a key finding in identifying why the reinforcement helix may contribute to overall section failure. With the damaged sites similar to these ones identified presently under crush loading, it therefore suggests that the helix is highly likely to experience localised cracking. These damage sites could be a result of bulging, whereby the external layers surrounding the helix will crush into the structure and, therefore, allow for conditions that produce localised crinkling, which make the marine hose to kink. With this evidence of localised damage, it could explain the reason for the hoses' failure while in service before their supposed end-of-lifetime point. During the reeling process, there will be a combination of tensile and torsional forces, as well as the continuous crush load on the section as it is reeled onto the drum, therefore offering prime conditions for these localised stress concentrators to allow for crack propagation and then reinforcement helix failure. Once the helix has failed, the section must be replaced, as the failed helix then offers another source of damage to its surrounding layers. As a result, this brings into question the suitability of steel as the reinforcement layer material of choice. To optimise the performance of the reinforcing helix layer, it may be suggested that other materials could be assessed for this localised damage, such as titanium for example.

Upon observing this evidence of localised damage of the reinforcement helix, as previously stated, the suitability of steel as a suitable material for this reinforcing layer became questionable. Therefore, it was deemed appropriate that an F.S analysis be carried out on layers of the hose line section composed of structural steel as its selected material. From the results obtained in Sections 4.1-4.6, it could be clearly demonstrated that the F.S for both the helix and liner needs to be improved upon. The average F.S for the reinforcement helix and liner was 0.7 and 0.6, respectively, to the nearest 1 d.p (decimal place). Thus, it can be determined that at this level of external collapsing pressure, at a value of $1.25 \times 10^{8} \mathrm{~Pa}$, that steel grade was an unsuitable choice of material at this magnitude of pressure, and the likelihood of mechanical failure at or beyond this pressure is significantly high. Contrastingly, an F.S analysis was carried out on one composite layer of the pipe section to compare the performance of the steel layers, with significantly more acceptable results. The composite-made holding plies were investigated for Factor of Safety and resulted in an average F.S value of 9.2, corrected to $1 \mathrm{~d}$.p. This comparison further enforces the notion that composite materials offer a remarkably high potential for application in the reeling process, as simulations demonstrate that composite materials perform well under trying conditions. It is vital that further work be carried out on these steel layers with the 
application of different materials, such to suggest a more conclusive recommendation of a higher-performing material to result in an increased F.S.

\section{Concluding Remarks}

This research was conducted based on a local design by utilising a finite element model approach for modelling the bonded marine hose. This numerical model was used to present result visualisations and nephographs for the $\mathrm{MBCH}$ model. The material properties presented in Section 2 were used to develop the novel material model. It was then utilised to test various design loads on the tubular structure that had been developed initially. Section 3 discussed the meshing details, boundary conditions and applied loads. The use of a tiny region for the local design allowed for less computational time and resources. This paper discusses the originality of the local design and the material modelling of marine bonded hoses in the oil and gas industry, as well as enhanced modelling techniques for marine composites. Other modelling methods that should be investigated further were suggested. In addition, some aspects of the intended hose were highlighted for additional research and optimisation in order to attain a longer in-service life lifetime.

The model features a first in material modelling for the finite element modelling of marine hoses, which is used in local design. Flexible risers and pipelay analysis have both benefited from this technique. This method conserves computer resources, as it is costeffective, and has a high level of accuracy. The hose model was also subjected to extensive local design for reeled and unreeled parts. The examination of the effect of compression loads on marine hoses was the second novelty. Some loadings are caused by the vessel's load response and the influence of fluid density on marine hoses. Furthermore, this research looked into the use of composites on multi-layered bonded structures. Finally, the model shows how a bonded tubular pipe behaves under pressure loads using design pressures and in the bending scenario by analysing deflections under burst and collapse loads.

From this study, the following conclusions and recommendations are made:

(1) Firstly, the load analysis on the helix spring-reinforcing of reeling hose is innovative. It can be observed that both the internal and external pressure tests are critical parts of the design process for marine bonded hoses. As proffered in Section 4, the higher the pressure, the higher the components for the maximum deformations, maximum strains and the von Mises stresses of the marine hose.

(2) The numerical investigation shows that the marine hose is capable of withstanding high-pressure load cases. With combined loadings on the $\mathrm{MBCH}$, a detailed investigation is recommended to look at the effect of the composite materials on each layer. Additionally, a load analysis is suggested with combined loadings on the marine hose in further studies to improve on its innovativeness. It is recommended that a detailed mesh convergence is carried out. In the present work, we had to reduce the computational work, so the content presented focused on the key aspects captured from the initial mesh study. However, it is noteworthy to state that there is the need to further conduct the mesh convergence in a more robust study. The present study is multi-layered and had challenges with licenses due to element sizes, element numbers, different layer sizes and different layers, as well as different geometries. For instance, the spring layers are spiral with cylindrical cross-sections with higher angles. Further work can include hoses with nipple /end-fitting built into the hose ends.

(3) Deformations in the structure were discovered after studying the marine hose under operating conditions. This can be reduced by strengthening the marine hose, employing lighter materials with a high strength-to-weight ratio, such as composites, or applying hydrodynamic loads to the hose. For instance, the reeling operation should also be performed under operating pressure rather than design pressure, as the study demonstrates that design pressure can be quite high. In future investigations, it is also suggested that researchers employ an explicit code that runs faster for modelling higher failure scenarios. Additionally, simpler schemes could be used in future studies 
that consider the symmetry and simplicity of sections of the marine hose model to reduce the utilisation of its computational resources.

(4) This study showed areas of the designed hose tubular structure that need to be optimised to achieve a longer in-service life span. It is critical to optimise the hose model and examine the helix further based on the helix reinforcement results. The tensions along the hose sections are likewise represented by the helix reinforcement, according to the study's findings. Since there are composite materials used, and the failure of them is part of the study, higher failure criteria should be used in future studies. However, this approach was not chosen in the present study due to its scope. Researchers should also accommodate failure modes in composites, such as delamination, material rubber models, matrix cracks and material hardening considerations.

(5) The study is important to determine the potential failure mechanisms of the structure under the state stated in actual hose-riser failure cases. The stress study on these hose sections can be used to further enhance the global design model for structural verification and postprocessing in future research. In fact, the load analysis of the marine hose section is conducted based on the representative load. Further research on the operation process (dynamic/transient mode) in the FEA, and the global design of the marine bonded hose under marine operations, such as reeling, are also suggested.

Author Contributions: Conceptualisation, C.V.A., C.C. and A.C.O.; methodology, C.V.A., C.C., H.O.B., Z.G. and A.C.O.; software, C.V.A., C.C., H.O.B., Z.G. and A.C.O.; validation, C.V.A., C.C., H.O.B., Z.G. and A.C.O.; formal analysis, C.V.A., C.C., H.O.B., Z.G. and A.C.O.; investigation, C.V.A., C.C., H.O.B., Z.G. and A.C.O.; resources, C.V.A.; data curation, C.V.A., C.C., H.O.B., Z.G. and A.C.O.; writing-original draft preparation, C.V.A. and C.C.; writing-review and editing, C.V.A., C.C., H.O.B., Z.G. and A.C.O.; visualisation, C.V.A., C.C., H.O.B., Z.G. and A.C.O.; supervision, C.V.A. and A.C.O.; project administration, C.V.A.; funding acquisition, C.V.A. All authors have read and agreed to the published version of the manuscript.

Funding: The funding support of the Department of Engineering, Lancaster University, UK, as well as the Engineering and Physical Sciences Research Council (EPSRC)'s Doctoral Training Grant (DTG), UK, are highly appreciated. Also, the funding of the Overseas Postgraduate Scholarship by the Niger Delta Development Commission (NDDC), Port Harcourt, Nigeria and the support of the Standards Organisation of Nigeria (SON), Abuja, Nigeria, are both appreciated. The article processing charges (APC) for this article was funded by author 1- C.V.A., with the support of MDPI's Journal of Composite Science (JCS).

Institutional Review Board Statement: Not applicable.

Informed Consent Statement: Not applicable.

Data Availability Statement: The data supporting the reported results cannot be shared at this time, as they are being used in producing more publications on this research.

Acknowledgments: The authors acknowledge the technical support of Lancaster University Engineering Department, particularly the supervisory leads on the project. The research reported in this paper is part of a PhD research project in the Lancaster University Engineering Department. Some aspect of the work was undertaken in a BEng Project. We appreciate the support of the Lancaster University Library staff, especially during the COVID-19 pandemic. We also acknowledge Jonathan Petit of Trelleborg, Oil and Marine Department, for the permission to use the image in Figure 1 of Trelleborg's marine hose. We are very grateful to the anonymous reviewers for the feedback on this submission which improved the quality of this manuscript. We also recognise the journal editors for the support in the production of this manuscript.

Conflicts of Interest: The authors declare no conflict of interest. The funders had no role in the design of the study; in the collection, analyses, or interpretation of data; in the writing of the manuscript, or in the decision to publish the results. 


\section{Appendix A}

The analytical model used in the validation of the spring model is based on some spring engineering variables. These equations, developed by Wahl [84], were utilised in the design formulas. Using these spring Equations (A1)-(A10) as detailed in $[89,90]$, with the parameters defined in Table A1. The analytical model validation for the helix reinforcement can be obtained from the spring constant, $\mathrm{k}$ [21]. Both the helix shear modulus and the helix or spring's geometry were first computed using Equations (A1) and (A2), then imputed into Equation (A3) to obtain $\mathrm{k}$. The helix spring in this study is designed using a steel material, which is isotropic in nature, as considered in Equation (A2).

$$
\begin{aligned}
D & =D_{\text {outer }}-d \\
G & =\frac{E}{2(1+v)} \\
k & =\frac{G d^{4}}{8 D^{3} n_{a}}
\end{aligned}
$$

The helix reinforcement geometry was designed using key parameters. These were also validated analytically using the helix reinforcement pitch, the rise angle and the solid height, as is depicted in Figure 7, by using the expressions in Equations (A4)-(A6).

$$
\begin{gathered}
\text { Coil }_{\text {pitch }}=\frac{L_{\text {free }}}{n_{a}} \\
L_{\text {solid }}=n_{t} d \\
\theta=\operatorname{atan}\left[\frac{\text { Coil }_{\text {pitch }}}{\pi D}\right]
\end{gathered}
$$

The force and stress computations for the helix reinforcement were also analytically computed using Wahl correction factor, $\mathrm{W}$, in the analytical model. These are covered by the expressions in Equations (A7)-(A10), and analytically solved for the helix reinforcement.

$$
\begin{gathered}
C=\frac{D}{d} \\
F_{\text {max }}=k\left(L_{\text {free }}-L_{\text {solid }}\right) \\
\tau_{\text {max }}=\frac{8 W D}{\pi d^{3}} F_{\text {max }} \\
W=\frac{4 C-1}{4 C-4}+\frac{0.615}{C}
\end{gathered}
$$

Table A1. Parameters for spring engineering variables utilised in design equations. (Source: [89]).

\begin{tabular}{cc}
\hline Parameters & Abbreviation \\
\hline Helix diameter ratio & $\mathrm{C}$ \\
Helix or spring wire diameter & $\mathrm{d}$ \\
Helix or spring outside diameter & $\mathrm{D}_{\text {outer }}$ \\
Mean diameter of spring & $\mathrm{D}$ \\
Young's modulus of material & $\mathrm{E}$ \\
Max force at solid & $\mathrm{F}_{\max }$ \\
Shear modulus of material & $\mathrm{G}$ \\
Free length & $\mathrm{L}_{\text {free }}$ \\
Wire length & $\mathrm{L}_{\text {wire }}$ \\
Solid height & $\mathrm{L}_{\text {solid }}$ \\
Maximum displacement & $\mathrm{L}_{\text {def }}$ \\
\hline
\end{tabular}


Table A1. Cont.

\begin{tabular}{cc}
\hline Parameters & Abbreviation \\
\hline Maximum load possible & $\mathrm{L}_{\max }$ \\
Wahl correction factor & $\mathrm{W}$ \\
Spring Constant & $\mathrm{k}$ \\
Active coils & $\mathrm{n}_{\mathrm{a}}$ \\
Total coils & $\mathrm{n}_{\mathrm{t}}$ \\
Density of material & $\mathrm{p}$ \\
Poisson ratio of material & $\mathrm{V}$ \\
Rise angle of spring coils & $\theta$ \\
Maximum shear stress & \multicolumn{2}{c}{$\tau_{\max }$} \\
\hline
\end{tabular}

\section{References}

1. Liu, B.; Fu, D.; Zhang, Y.; Chen, X. Experimental and numerical study on the wave force calculation of a partially immersed horizontal cylindrical float. Int. J. Nav. Archit. Ocean. Eng. 2020, 12, 733-742. [CrossRef]

2. Ja'E, I.A.; Ali, M.O.A.; Yenduri, A.; Nizamani, Z.; Nakayama, A. Optimisation of mooring line parameters for offshore floating structures: A review paper. Ocean Eng. 2022, 247, 110644. [CrossRef]

3. Toh, W.; Bin Tan, L.; Jaiman, R.K.; Tay, T.E.; Tan, V.B.C. A comprehensive study on composite risers: Material solution, local end fitting design and global response. Mar. Struct. 2018, 61, 155-169. [CrossRef]

4. Pham, D.-C.; Sridhar, N.; Qian, X.; Sobey, A.; Achintha, M.; Shenoi, A. A review on design, manufacture and mechanics of composite risers. Ocean Eng. 2016, 112, 82-96. [CrossRef]

5. Ochoa, O.O.; Technology, O. Composite Riser Experience and Design Guidance; MMS Project Number 490, Texas, USA. 2006. Available online: https://www.bsee.gov/sites/bsee.gov/files/tap-technical-assessment-program//490aa.pdf (accessed on 13 January 2022).

6. Ochoa, O.; Salama, M. Offshore composites: Transition barriers to an enabling technology. Compos. Sci. Technol. 2005, 65, 2588-2596. [CrossRef]

7. Rubino, F.; Nisticò, A.; Tucci, F.; Carlone, P. Marine Application of Fiber Reinforced Composites: A Review. J. Mar. Sci. Eng. 2020, 8, 26. [CrossRef]

8. Van Onna, M.; O’Brien, P. A New Thermoplastic Composite Riser for Deepwater Application. In Proceedings of the Subsea UK Conference, Aberdeen, UK; 2011; pp. 1-23. Available online: https://www.subseauk.com/documents/martinvanonnasubsea201 1presentation.pdf (accessed on 13 January 2022).

9. Van Onna, M.; Lyon, J. Installation of World's 1st Subsea Thermoplastic Composite Pipe Jumper on Alder. 2017. Available online: https:/ / www.subseauk.com/documents/presentations / martin $\% 20$ van $\% 20$ onna $\% 20-\% 20$ fields $\% 20$ of $\% 20$ the $\% 20$ future $\%$ 20-\%20airborne.pdf (accessed on 13 January 2022).

10. Roberts, D.; Hatton, S.A. Development and Qualification of End Fittings for Composite Riser Pipe. In Proceedings of the Offshore Technology Conference, Houston, TX, USA, 6-9 May 2013. [CrossRef]

11. Beyle, A.I.; Gustafson, C.G.; Kulakov, V.L.; Tarnopol'Skii, Y.M. Composite risers for deep-water offshore technology: Problems and prospects. 1. Metal-composite riser. Polym. Mech. 1997, 33, 403-414. [CrossRef]

12. Amaechi, C.V.; Agbomerie, C.O.; Sotayo, A.; Wang, F.; Hou, X.; Ye, J. Recycling of Renewable Composite Materials in the Offshore Industry. In Encyclopedia of Renewable and Sustainable Materials; Elsevier: Amsterdam, The Netherlands, 2020; pp. 583-613. [CrossRef]

13. Amaechi, C.-V.; Agbomerie, C.-O.; Orok, E.-O.; Job, S.; Ye, J. Economic aspects of fiber reinforced polymer composite recycling. In Reference Module in Materials Science and Materials Engineering; Elsevier: Amsterdam, The Netherlands, 2019. [CrossRef]

14. Sadeghi, K. An Overview of Design, Analysis, Construction and Installation of Offshore Petroleum Platforms Suitable for Cyprus Oil/Gas Fields. GAU J. Soc. Appl. Sci. 2007, 2, 1-16. Available online: https://cemtelecoms.iqpc.co.uk/media/6514/786.pdf (accessed on 6 January 2022).

15. Odijie, A.C.; Wang, F.; Ye, J. A review of floating semisubmersible hull systems: Column stabilized unit. Ocean Eng. 2017, 144, 191-202. [CrossRef]

16. Hirdaris, S.; Bai, W.; Dessi, D.; Ergin, A.; Gu, X.; Hermundstad, O.; Huijsmans, R.; Iijima, K.; Nielsen, U.; Parunov, J.; et al. Loads for use in the design of ships and offshore structures. Ocean Eng. 2014, 78, 131-174. [CrossRef]

17. Amaechi, C.V.; Wang, F.; Odijie, A.C.; Ye, J. Numerical investigation on mooring line configurations of a Paired Column Semisubmersible for its global performance in deep water condition. Ocean. Eng. 2022; in press. [CrossRef]

18. Islam, A.S.; Jameel, M.; Jumaat, M.Z.; Shirazi, S.; Salman, F.A. Review of offshore energy in Malaysia and floating Spar platform for sustainable exploration. Renew. Sustain. Energy Rev. 2012, 16, 6268-6284. [CrossRef]

19. Yu, L.C.; King, L.S.; Hoon, A.T.C.; Yean, P.C.C. A Review Study of Oil and Gas Facilities for Fixed and Floating Offshore Platforms. Res. J. Appl. Sci. Eng. Technol. 2015, 10, 672-679. [CrossRef]

20. Amaechi, C.V. Novel Design, Hydrodynamics and Mechanics of Marine Hoses in Oil/Gas Applications. Ph.D. Thesis, Lancaster University, Engineering Department, Lancaster, UK, 2022. 
21. Amaechi, C.V.; Chesterton, C.; Butler, H.O.; Gu, Z.; Odijie, A.C.; Wang, F.; Hou, X.; Ye, J. Finite Element Modelling on the Mechanical Behaviour of Marine Bonded Composite Hose (MBCH) under Burst and Collapse. J. Mar. Sci. Eng. 2022, $10,151$. [CrossRef]

22. Amaechi, C.V.; Chesterton, C.; Butler, H.O.; Wang, F.; Ye, J. Review on the design and mechanics of bonded marine hoses for Catenary Anchor Leg Mooring (CALM) buoys. Ocean Eng. 2021, 242, 110062. [CrossRef]

23. Amaechi, C.V.; Wang, F.; Ye, J. An Overview on Bonded Marine Hoses for sustainable fluid transfer and (un)loading operations via Floating Offshore Structures (FOS). J. Mar. Sci. Eng. 2021, 9, 1236. [CrossRef]

24. Amaechi, C.V.; Wang, F.; Ye, J. Mathematical Modelling of Bonded Marine Hoses for Single Point Mooring (SPM) Systems, with Catenary Anchor Leg Mooring (CALM) Buoy application-A Review. J. Mar. Sci. Eng. 2021, 9, 1179. [CrossRef]

25. Amaechi, C.V.; Wang, F.; Ja'e, I.A.; Aboshio, A.; Odijie, A.C. A literature review on the technologies of bonded hoses for marine applications. Ships Offshore Struct. 2022; in press. [CrossRef]

26. Muren, J. PSA-Norway Flexible Pipe: Failure Modes, Inspection, Testing and Monitoring; PSA Norway: Asker, Norway, 2007; Available online: https:/ / www.ptil.no/contentassets/a4c8365164094826a24499ef9f22742b / p5996rpt01rev02cseaflex_janmuren. pdf (accessed on 29 July 2021).

27. Drumond, G.P.; Pasqualino, I.; Pinheiro, B.; Estefen, S. Pipelines, risers and umbilicals failures: A literature review. Ocean Eng. 2018, 148, 412-425. [CrossRef]

28. Simonsen, A. Inspection and Monitoring Techniques for Un-bonded Flexible Risers and Pipelines. Master's Thesis, University of Stavanger, Stavanger, Norway, 2014. Available online: http:/ /hdl.handle.net/11250/219671 (accessed on 27 August 2021).

29. Muren, J.; Caveny, K.; Eriksen, M.; Viko, N.G.; MÜLler-Allers, J.; JØRgen, K.U. Un-Bonded Flexible Risers-Recent Field Experience and Actions for Increased Robustness; 0389-26583-U-0032, Revision 5.0; PSA: Asker, Norway, 2013; Volume 2, pp. 1-78. Available online: https:/ / www.ptil.no/contentassets / c2a5bd00e8214411ad5c4966009d6ade/un-bonded-flexible-risers--recent-fieldexperience-and-actions--for-increased-robustness.pdf (accessed on 17 June 2021).

30. Løtveit, S.A.; Muren, J.; Nilsen-Aas, C. Bonded Flexibles-State of the Art Bonded Flexible Pipes; 26583U-1161480945-354, Revision 2.0, Approved on 17.12.2018; PSA: Asker, Norway, 2018; pp. 1-75. Available online: https://www.4subsea.com/wp-content/ uploads/2019/01/PSA-Norway-State-of-the-art-Bonded-Flexible-Pipes-2018_4Subsea.pdf (accessed on 17 June 2021).

31. Gillett, N. Design and Development of a Novel Deepwater Composite Riser. BEng Thesis, Engineering Department, Lancaster University, Lancaster, UK, 2018.

32. Kim, W.K. Composite Production Riser Assessment. Ph.D. Thesis, Texas A \& M University, College Station, TX, USA, 2007. Available online: https:/ / core.ac.uk/download/pdf/4272879.pdf (accessed on 13 January 2022).

33. Akula, V.M.K. Global-Local Analysis of a Composite Riser. In Proceedings of the ASME 2014 Pressure Vessels and Piping Conference; Volume 3: Design and Analysis, Anaheim, CA, USA, 20-24 July 2014; pp. 1-9. [CrossRef]

34. Bai, Y.; Xu, F.; Cheng, P.; Badaruddin, M.F.; Ashri, M. Burst Capacity of Reinforced Thermoplastic Pipe (RTP) Under Internal Pressure. In Proceedings of the International Conference on Offshore Mechanics and Arctic Engineering; Volume 4: Pipeline and Riser Technology, Rotterdam, The Netherlands, 19-24 June 2011; pp. 281-288. [CrossRef]

35. Wang, C.; Shankar, K.; Morozov, E.V. Global design and analysis of deep sea FRP composite risers under combined environmental loads. Adv. Compos. Mater. 2015, 26, 79-98. [CrossRef]

36. Wang, C.; Sun, M.; Shankar, K.; Xing, S.; Zhang, L. CFD Simulation of Vortex Induced Vibration for FRP Composite Riser with Different Modeling Methods. Appl. Sci. 2018, 8, 684. [CrossRef]

37. Amaechi, C.V.; Wang, F.; Hou, X.; Ye, J. Strength of submarine hoses in Chinese-lantern configuration from hydrodynamic loads on CALM buoy. Ocean Eng. 2018, 171, 429-442. [CrossRef]

38. Amaechi, C.V.; Ye, J.; Hou, X.L.; Wang, F.-C. Sensitivity Studies on Offshore Submarine Hoses on CALM Buoy with Comparisons for Chinese-Lantern and Lazy-S Configuration. Paper OMAE2019-96755. In Proceedings of the 38th International Conference on Ocean, Offshore and Arctic Engineering, Glasgow, Scotland, 9-14 June 2019.

39. Amaechi, C.V.; Wang, F.; Ye, J. Numerical Assessment on the Dynamic Behaviour of Submarine Hoses Attached to CALM Buoy Configured as Lazy-S under Water Waves. J. Mar. Sci. Eng. 2021, 9, 1130. [CrossRef]

40. Amaechi, C.V.; Wang, F.; Ye, J. Understanding the fluid-structure interaction from wave diffraction forces on CALM buoys: Numerical and analytical solutions. Ships Offshore Struct. 2022; ahead-of-print. [CrossRef]

41. Amaechi, C.V.; Wang, F.; Ye, J. Numerical studies on CALM buoy motion responses and the effect of buoy geometry cum skirt dimensions with its hydrodynamic waves-current interactions. Ocean Eng. 2021, 244, 110378. [CrossRef]

42. Kang, Z.; Zhang, C.; Sun, L. Research on truncation method of FPSO and offloading system in model test. Appl. Ocean Res. 2017, 67, 94-108. [CrossRef]

43. Amaechi, C.V.; Wang, F.; Ye, J. Investigation on Hydrodynamic Characteristics, Wave-Current Interaction and Sensitivity Analysis of Submarine Hoses Attached to a CALM Buoy. J. Mar. Sci. Eng. 2022, 10, 120. [CrossRef]

44. Continental. Marine Hose Brochure; Dunlop Oil \& Marine, Continental Contitech Oil \& Gas: Grimsby, UK, 2020; Available online: https:/ / aosoffshore.com/wp-content/uploads/2020/02/ContiTech_Marine-Brochure.pdf (accessed on 17 February 2021).

45. Yokohama. Seaflex Yokohama Offshore Loading \& Discharge Hose; The Yokohama Rubber Co. Ltd.: Hiratsuka City, Japan, 2016; Available online: https:/ / www.y-yokohama.com/global/product/mb/pdf/resource/seaflex.pdf (accessed on 17 May 2021). 
46. Trelleborg. Oil \& Gas Solutions: Oil \& Gas Hoses for Enhanced Fluid Transfer Solutions; Trelleborg Fluid Handling Solutions, Oil \& Marine Hoses: Innovation and Safety for Oil \& Gas Transfer Systems; Trelleborg: Clemont-Ferrand, France, 2018; Volume 1, pp. $1-30$.

47. EMSTEC. EMSTEC Loading E Discharge Hoses for Offshore Moorings; EMSTEC: Rosengarten, Germany, 2016; Available online: https:// denialink.eu/pdf/emstec.pdf (accessed on 29 September 2021).

48. OIL. Offloading Hoses: Floating \& Submarine Hoses-OIL Hoses Brochure; Offspring International Limited: Dudley, UK, 2014; Available online: https: / www.offspringinternational.com/wp-content/uploads /2020/06/OIL-Offloading-Hoses-Brochure-2020-W.pdf (accessed on 12 July 2021).

49. Zhang, X.; Ni, W.; Sun, L. Fatigue Analysis of the Oil Offloading Lines in FPSO System under Wave and Current Loads. J. Mar. Sci. Eng. 2022, 10, 225. [CrossRef]

50. Amaechi, C.V.; Ye, J. A numerical modeling approach to composite risers for deep waters. In Proceedings of the ICCS20 20th International Conference on Composite Structures Proceedings, Paris, France, 4-7 September 2017; Structural and Computational Mechanics Book Series. Ferreira, A.J.M., Larbi, W., Deu, J.-F., Tornabene, F., Fantuzzi, N., Eds.; Societa Editrice Esculapio: Bologna, Italy, 2017; pp. 262-263.

51. Amaechi, C.V.; Gillett, N.; Odijie, A.C.; Wang, F.; Hou, X.; Ye, J. Local and Global Design of Composite Risers on Truss SPAR Platform in Deep waters. In Proceedings of the 5th International Conference on Mechanics of Composites, Instituto Superior de Tecnico, Lisbon, Portugal, 1-4 July 2019; No. 20005. pp. 1-3. Available online: https:/ /eprints.lancs.ac.uk/id/eprint/136431/4 /Local_and_Global_analysis_of_Composite_Risers_MechComp2019_Conference_Victor.pdf (accessed on 22 December 2021).

52. Amaechi, C.V.; Gillett, N.; Odijie, A.C.; Hou, X.; Ye, J. Composite risers for deep waters using a numerical modelling approach. Compos. Struct. 2018, 210, 486-499. [CrossRef]

53. Amaechi, C.V.; Ye, J. Local tailored design of deep water composite risers subjected to burst, collapse and tension loads. Ocean Eng. 2021; in press. [CrossRef]

54. Xia, M.; Takayanagi, H.; Kemmochi, K. Analysis of multi-layered filament-wound composite pipes under internal pressure. Compos. Struct. 2001, 53, 483-491. [CrossRef]

55. Sun, C.T.; Li, S. Three-dimensional effective elastic constant for thick laminates. J. Compos. Mater. 1988, 22, 629-639. [CrossRef]

56. Ye, J.; Soldatos, K.P. Three-dimensional buckling analysis of laminated composite hollow cylinders and cylindrical panels. Int. J. Solids Struct. 1995, 32, 1949-1962. [CrossRef]

57. Bakaiyan, H.; Hosseini, H.; Ameri, E. Analysis of multi-layered filament-wound composite pipes under combined internal pressure and thermomechanical loading with thermal variations. Compos. Struct. 2009, 88, 532-541. [CrossRef]

58. Gao, Q.; Zhang, P.; Duan, M.; Yang, X.; Shi, W.; An, C.; Li, Z. Investigation on structural behavior of ring-stiffened composite offshore rubber hose under internal pressure. Appl. Ocean Res. 2018, 79, 7-19. [CrossRef]

59. Lassen, T.; Eide, A.L.; Meling, T.S. Ultimate Strength and Fatigue Durability of Steel Reinforced Rubber Loading Hoses. In Proceedings of the ASME 2010 29th International Conference on Ocean, Offshore and Arctic Engineering, Volume 5, Parts A and B, Shanghai, China, 6-11 June 2010; pp. 277-286. [CrossRef]

60. Tonatto, M.L.; Roese, P.B.; Tita, V.; Forte, M.M.; Amico, S.C. Offloading marine hoses: Computational and experimental analyses. In Woodhead Publishing Series in Composites Science and Engineering; Woodhead Publishing: Sawston, UK, 2018; pp. 389-416. [CrossRef]

61. Tonatto, M.L.; Tita, V.; Araujo, R.T.; Forte, M.M.; Amico, S.C. Parametric analysis of an offloading hose under internal pressure via computational modeling. Mar. Struct. 2017, 51, 174-187. [CrossRef]

62. Amaechi, C.V.; Wang, F.; Ye, J. Experimental Study on Motion Characterisation of CALM Buoy Hose System under Water Waves. J. Mar. Sci. Eng. 2022, 10, 204. [CrossRef]

63. Hassan, A.; Khan, R.; Khan, N.; Aamir, M.; Pimenov, D.; Giasin, K. Effect of Seawater Ageing on Fracture Toughness of Stitched Glass Fiber/Epoxy Laminates for Marine Applications. J. Mar. Sci. Eng. 2021, 9, 196. [CrossRef]

64. Rabelo, A.S. Estudo do Comportamento de Mangueiras Termoplásticas de Umbilicais Submarinos Submetidas a Carregamentos Mecânicos. Master's Thesis, Universidade Federal do Rio de Janeiro (UFRJ) \& COPPE, Department of Ocean Engineering ('Engenharia Oceânica'), COPPE/UFRJ, Rio de Janeiro, RJ, Brazil, 2013. Available online: https://w1files.solucaoatrio.net. br/atrio/ufrj-peno_upl//THESIS /6000252/2013_mestrando_alexandre_soares_rabelo_20200405214916875.pdf (accessed on 27 August 2021). (In Portuguese).

65. Gao, P.; Gao, Q.; An, C.; Zeng, J. Analytical modeling for offshore composite rubber hose with spiral stiffeners under internal pressure. J. Reinf. Plast. Compos. 2021, 40, 352-364. [CrossRef]

66. Lassen, T.; Lem, A.I.; Imingen, G. Load Response and Finite Element Modelling of Bonded Loading Hoses. In Proceedings of the ASME 2014 33rd International Conference on Ocean, Offshore and Arctic Engineering; Volume 6A: Pipeline and Riser Technology, San Francisco, CA, USA, 8-13 August 2014. [CrossRef]

67. Tonatto, M.L.; Tita, V.; Forte, M.M.; Amico, S.C. Multi-scale analyses of a floating marine hose with hybrid polyaramid/polyamide reinforcement cords. Mar. Struct. 2018, 60, 279-292. [CrossRef]

68. Tonatto, M.L.; Tita, V.; Amico, S.C. Composite spirals and rings under flexural loading: Experimental and numerical analysis. J. Compos. Mater. 2020, 54, 2697-2705. [CrossRef]

69. Tonatto, M.L.; Forte, M.M.; Tita, V.; Amico, S.C. Progressive damage modeling of spiral and ring composite structures for offloading hoses. Mater. Des. 2016, 108, 374-382. [CrossRef] 
70. OCIMF. A Study into Crane Loads Associated with Hose Handling at Offshore Terminals, OCIMF Info Paper, Version 6; Oil Companies International Marine Forum (OCIMF): London, UK, 2020; Available online: https://www.ocimf.org/media/58339/OC_ INFOPAPER2961_CRANE_V6.pdf (accessed on 29 July 2021).

71. OCIMF. Single Point Mooring Maintenace and Operations Guide (SMOG); Witherby \& Co. Ltd.: London, UK, 1995.

72. OCIMF. Guide to Manufacturing and Purchasing Hoses for Offshore Moorings (GMPHOM); Witherby Seamanship International Ltd.: Livingstone, UK, 2009.

73. Gonzalez, G.M.; de Sousa, J.R.M.; Sagrilo, L.V.S. A study on the axial behavior of bonded flexible marine hoses. Mar. Syst. Ocean Technol. 2016, 11, 31-43. [CrossRef]

74. Cole, C. A Global and Local Analysis of Offshore Composite Material Reeling Pipeline Hose, with FPSO Mounted Reel Drum. BEng Thesis, Lancaster University, Engineering Department, Lancaster, UK, 2020.

75. Zhou, Y.; Duan, M.; Ma, J.; Sun, G. Theoretical analysis of reinforcement layers in bonded flexible marine hose under internal pressure. Eng. Struct. 2018, 168, 384-398. [CrossRef]

76. Tonatto, M.L.; Forte, M.M.; Amico, S.C. Compressive-tensile fatigue behavior of cords/rubber composites. Polym. Test. 2017, 61, 185-190. [CrossRef]

77. ANSYS. ANSYS Meshing User's Guide; Release 18.2; ANSYS Inc.: Canonsburg, WA, USA, 2017.

78. ANSYS. ANSYS Modeling and Meshing Guide; Release 9.0; ANSYS Inc.: Canonsburg, WA, USA, 2004; Available online: http: / / dl.mycivil.ir/reza/Ansys\%20Modeling\%20And\%20Meshing\%20Guide.pdf (accessed on 24 February 2022).

79. ANSYS. ANSYS Meshing User's Guide; Release 15.0; ANSYS Inc.: Canonsburg, WA, USA, 2013; Available online: https:/ /www. academia.edu/27974461/ANSYS_Meshing_Users_Guide (accessed on 19 August 2021).

80. API. API 17K: Specification for Bonded Flexible Pipe, 3rd ed.; American Petroleum Institute (API): Texas City, TX, USA, 2017.

81. ISO. ISO 13628-10 (Identical to API 17K), Petroleum and Natural Gas Industries-Design and Operation of Subsea Production Systems-Part 10: Specification for Bonded Flexible Pipe; International Organization for Standardization (ISO): Geneva, Switzerland, 2005.

82. DNVGL. DNVGL-OS-E403 Offshore Loading Buoys, No. July; Det Norske Veritas \& Germanischer Lloyd: Oslo, Norway, 2015; Available online: https:/ /rules.dnv.com/docs/pdf/DNV/os/2015-07/DNVGL-OS-E403.pdf (accessed on 29 July 2021).

83. ABS. Rules for Building and Classing—Single Point Moorings; American Bureau of Shipping (ABS): Houston, TX, USA, 2014; Available online: https:/ / ww2.eagle.org/content/dam/eagle/rules-and-guides/current/offshore/8_rules-forbuildingandclassingsinglepointmoor 2021/spm-rules-jan21.pdf (accessed on 29 July 2021).

84. Wahl, A.M. Mechanical Springs, 1st ed.; Penton Publishing Company: Cleveland, OH, USA, 1944.

85. Gu, Z.; Hou, X.; Keating, E.; Ye, J. Non-linear finite element model for dynamic analysis of high-speed valve train and coil collisions. Int. J. Mech. Sci. 2020, 173, 105476. [CrossRef]

86. Gu, Z.; Hou, X.; Ye, J. Design and analysis method of nonlinear helical springs using a combining technique: Finite element analysis, constrained Latin hypercube sampling and genetic programming. Proc. Inst. Mech. Eng. Part C J. Mech. Eng. Sci. 2021, 235, 5917-5930. [CrossRef]

87. Amaechi, C.V.; Adefuye, E.F.; Oyetunji, A.K.; Ja'E, I.A.; Adelusi, I.; Odijie, A.C.; Wang, F. Numerical Study on Plastic Strain Distributions and Mechanical Behaviour of a Tube under Bending. Inventions 2022, 7, 9. [CrossRef]

88. Ye, J.; Cai, H.; Liu, L.; Zhai, Z.; Amaechi, C.V.; Wang, Y.; Wan, L.; Yang, D.; Chen, X.; Ye, J. Microscale intrinsic properties of hybrid unidirectional/woven composite laminates: Part I experimental tests. Compos. Struct. 2020, 262, 113369. [CrossRef]

89. SpringHouston. Spring Design Equations; Spring Engineers of Houston: Houston, TX, USA, 2020; Available online: http: //www.springhouston.com/spring-information/spring-engineering.html (accessed on 20 February 2022).

90. SpringHouston. How to Design a Spring: An Important but Overview; Spring Engineers of Houston: Houston, TX, USA, 2021; Available online: http:/ / www.springhouston.com/how-to-design-a-spring.html (accessed on 20 February 2022). 